Cochrane Database of Systematic Reviews

\title{
Tranexamic acid for upper gastrointestinal bleeding (Review)
}

Bennett C, Klingenberg SL, Langholz E, Gluud LL

Bennett C, Klingenberg SL, Langholz E, Gluud LL.

Tranexamic acid for upper gastrointestinal bleeding.

Cochrane Database of Systematic Reviews 2014, Issue 11. Art. No.: CD006640.

DOI: 10.1002/14651858.CD006640.pub3.

www.cochranelibrary.com 
TABLE OF CONTENTS

HEADER 1

ABSTRACT

PLAIN LANGUAGE SUMMARY

SUMMARY OF FINDINGS

BACKGROUND

OBJECTIVES

METHODS

RESULTS

Figure 1.

Figure 2.

Figure 3.

Figure 4.

DISCUSSION

AUTHORS' CONCLUSIONS

ACKNOWLEDGEMENTS

REFERENCES

CHARACTERISTICS OF STUDIES

DATA AND ANALYSES

Analysis 1.1. Comparison 1 Tranexamic acid vs placebo, Outcome 1 Mortality.

Analysis 1.2. Comparison 1 Tranexamic acid vs placebo, Outcome 2 Mortality scenario analysis, treatment failure if participant missing.

Analysis 1.3. Comparison 1 Tranexamic acid vs placebo, Outcome 3 Mortality in trials with low risk of bias. ...........................

Analysis 1.4. Comparison 1 Tranexamic acid vs placebo, Outcome 4 Mortality in relation to endoscopic therapy. .....................

Analysis 1.5. Comparison 1 Tranexamic acid vs placebo, Outcome 5 Mortality in relation to language of publication. ..............

Analysis 1.6. Comparison 1 Tranexamic acid vs placebo, Outcome 6 Rebleeding.

Analysis 1.7. Comparison 1 Tranexamic acid vs placebo, Outcome 7 Rebleeding scenario analysis, treatment failure if participant missing.

Analysis 1.8. Comparison 1 Tranexamic acid vs placebo, Outcome 8 Rebleeding in trials with low risk of bias. ........................

Analysis 1.9. Comparison 1 Tranexamic acid vs placebo, Outcome 9 Rebleeding in relation to endoscopic therapy. ................ Analysis 1.10. Comparison 1 Tranexamic acid vs placebo, Outcome 10 Rebleeding in relation to language of publication. ...... Analysis 1.11. Comparison 1 Tranexamic acid vs placebo, Outcome 11 Myocardial infarction, pulmonary embolism and cerebral infarction.

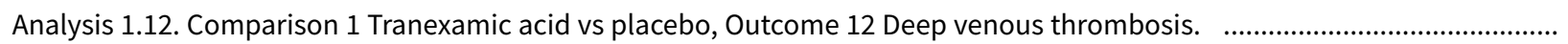

Analysis 1.13. Comparison 1 Tranexamic acid vs placebo, Outcome 13 Any thromboembolic event.

Analysis 1.14. Comparison 1 Tranexamic acid vs placebo, Outcome 14 Surgery.

Analysis 1.15. Comparison 1 Tranexamic acid vs placebo, Outcome 15 Transfusion required.

Analysis 2.1. Comparison 2 Tranexamic acid vs cimetidine or lansoprazole, Outcome 1 Mortality.

Analysis 2.2. Comparison 2 Tranexamic acid vs cimetidine or lansoprazole, Outcome 2 Bleeding.

Analysis 2.3. Comparison 2 Tranexamic acid vs cimetidine or lansoprazole, Outcome 3 Surgery.

Analysis 2.4. Comparison 2 Tranexamic acid vs cimetidine or lansoprazole, Outcome 4 Transfusion. ADDITIONAL TABLES

APPENDICES

WHAT'S NEW

CONTRIBUTIONS OF AUTHORS

DECLARATIONS OF INTEREST

SOURCES OF SUPPORT

DIFFERENCES BETWEEN PROTOCOL AND REVIEW

INDEX TERMS 
[Intervention Review]

\title{
Tranexamic acid for upper gastrointestinal bleeding
}

\author{
Cathy Bennett ${ }^{1}$, Sarah Louise Klingenberg${ }^{2}$, Ebbe Langholz ${ }^{3}$, Lise Lotte Gluud 4
}

${ }^{1}$ Centre for Technology Enabled Health Research (CTEHR), Coventry University, Coventry, UK. ${ }^{2}$ Cochrane Hepato-Biliary Group, Copenhagen Trial Unit, Centre for Clinical Intervention Research, Department 7812, Rigshospitalet, Copenhagen University Hospital, Copenhagen, Denmark. ${ }^{3}$ Department F, Gastroenterology Section, Gentofte University Hospital, Hellerup, Denmark. ${ }^{4} \mathrm{Gastrounit}$, Medical Division, Copenhagen University Hospital Hvidovre, Hvidovre, Denmark

Contact address: Lise Lotte Gluud, Gastrounit, Medical Division, Copenhagen University Hospital Hvidovre, Kettegaards Alle, Hvidovre, 2650, Denmark. liselottegluud@yahoo.dk.

Editorial group: Cochrane Upper GI and Pancreatic Diseases Group.

Publication status and date: New search for studies and content updated (no change to conclusions), published in Issue 11, 2014.

Citation: Bennett C, Klingenberg SL, Langholz E, Gluud LL. Tranexamic acid for upper gastrointestinal bleeding. Cochrane Database of Systematic Reviews 2014, Issue 11. Art. No.: CD006640. DOI: 10.1002/14651858.CD006640.pub3.

Copyright $@ 2014$ The Cochrane Collaboration. Published by John Wiley \& Sons, Ltd.

\section{A B S T R A C T}

\section{Background}

Tranexamic acid reduces haemorrhage through its antifibrinolytic effects. In a previous version of the present review, we found that tranexamic acid may reduce mortality. This review includes updated searches and new trials.

\section{Objectives}

To assess the effects of tranexamic acid versus no intervention, placebo or other antiulcer drugs for upper gastrointestinal bleeding.

\section{Search methods}

We updated the review by performing electronic database searches (Cochrane Central Register of Controlled Trials (CENTRAL), MEDLINE, EMBASE, Science Citation Index) and manual searches in July 2014.

\section{Selection criteria}

Randomised controlled trials, irrespective of language or publication status.

\section{Data collection and analysis}

We used the standard methodological procedures of the The Cochrane Collaboration. All-cause mortality, bleeding and adverse events were the primary outcome measures. We performed fixed-effect and random-effects model meta-analyses and presented results as risk ratios (RRs) with 95\% confidence intervals (Cls) and used $\mathrm{I}^{2}$ as a measure of between-trial heterogeneity. We analysed tranexamic acid versus placebo or no intervention and tranexamic acid versus antiulcer drugs separately. To analyse sources of heterogeneity and robustness of the overall results, we performed subgroup, sensitivity and sequential analyses.

\section{Main results}

We included eight randomised controlled trials on tranexamic acid for upper gastrointestinal bleeding. Additionally, we identified one large ongoing pragmatic randomised controlled trial from which data are not yet available. Control groups were randomly assigned to placebo (seven trials) or no intervention (one trial). Two trials also included a control group randomly assigned to antiulcer drugs (lansoprazole or cimetidine). The included studies were published from 1973 to 2011. The number of participants randomly assigned ranged from 47 to 216 (median 204). All trials reported mortality. In total, 42 of 851 participants randomly assigned to tranexamic acid and 71 of 850 in the control group died (RR $0.60,95 \% \mathrm{Cl} 0.42$ to 0.87 ; P value $0.007 ; \mathrm{I}^{2}=0 \%$ ). The analysis was not confirmed when all participants in the intervention group with missing outcome data were included as treatment failures, or when the analysis was limited to trials with low risk of attrition bias. Rebleeding was diagnosed for 117 of 826 participants in the tranexamic acid group and for 146 of 825 participants in the 
control group (RR $0.80,95 \% \mathrm{Cl} 0.64$ to $1.00 ; \mathrm{P}$ value $0.07 ; \mathrm{I}^{2}=49 \%$ ). We were able to evaluate the risk of serious adverse events on the basis of only four trials. Our analyses showed 'no evidence of a difference between tranexamic acid and control interventions regarding the risk of thromboembolic events.' Tranexamic acid appeared to reduce the risk of surgery in a fixed-effect meta-analysis (RR $0.73,95 \% \mathrm{Cl} 0.56$ to 0.95), but this result was no longer statistically significant in a random-effects meta-analysis ( $\mathrm{RR} 0.61,95 \% \mathrm{Cl} 0.35$ to 1.04 ; $\mathrm{P}$ value 0.07 ). No difference was apparent between tranexamic acid and placebo in the assessment of transfusion (RR $1.02,95 \% \mathrm{Cl} 0.94$ to $1.11 ; \mathrm{I}^{2}=0 \%$ ), and meta-analyses that compared tranexamic acid versus antiulcer drugs did not identify beneficial or detrimental effects of tranexamic acid for any of the outcomes assessed.

\section{Authors' conclusions}

This review found that tranexamic acid appears to have a beneficial effect on mortality, but a high dropout rate in some trials means that we cannot be sure of this until the findings of additional research are published. At the time of this update in 2014, one large study (8000 participants) is in progress, so this review will be much more informative in a few years. Further examination of tranexamic acid would require inclusion of high-quality randomised controlled trials. Timing of randomisation is essential to avoid attrition bias and to limit the number of withdrawals. Future trials may use a pragmatic design and should include all participants with suspected bleeding or with endoscopically verified bleeding, as well as a tranexamic placebo arm and co-administration of pump inhibitors and endoscopic therapy. Assessment of outcome measures in such studies should be clearly defined. Endoscopic examination with appropriate control of severe bleeding should be performed, as should endoscopic verification of clinically significant rebleeding. In addition, clinical measures of rebleeding should be included. Other important outcome measures include mortality (30-day or in-hospital), need for emergency surgery or blood transfusion and adverse events (major or minor).

\section{PLAIN LANGUAGE SUMMARY}

\section{Tranexamic acid, an agent that promotes blood clotting, for serious or uncontrolled upper gastrointestinal bleeding}

\section{Background}

Upper gastrointestinal bleeding is a common reason for emergency hospital admission. The prognosis is serious. Some patients may die as the result of uncontrolled bleeding.

\section{Review question}

Tranexamic acid is an antifibrinolytic agent. This drug reduces the breakdown of fibrin; fibrin provides the framework for the formation of a blood clot, which is needed to stop the bleeding. Clinical trials suggest that tranexamic acid could reduce mortality in upper gastrointestinal bleeding.

\section{Study characteristics}

This review includes data from eight randomised trials on tranexamic acid. Two trials also assessed antiulcer drugs. Only one trial used additional endoscopic therapy, as the remaining trials were performed before this intervention was introduced into clinical practice.

\section{Key results}

These trials found that tranexamic acid appears to have a beneficial effect on mortality, but a high dropout rate in some trials means that we cannot be sure of these findings until additional research is published. Tranexamic acid did not reduce mortality in the trials that included antiulcer drugs or endoscopic therapy. Additional randomised controlled trials are needed before we can determine whether tranexamic acid has a beneficial effect on serious or uncontrolled upper gastrointestinal bleeding.

\section{Quality of the evidence}

Many patients who were randomly assigned were subsequently excluded from the assessment. The main source of bias was therefore attrition. The overall quality of the evidence was moderate to low. 


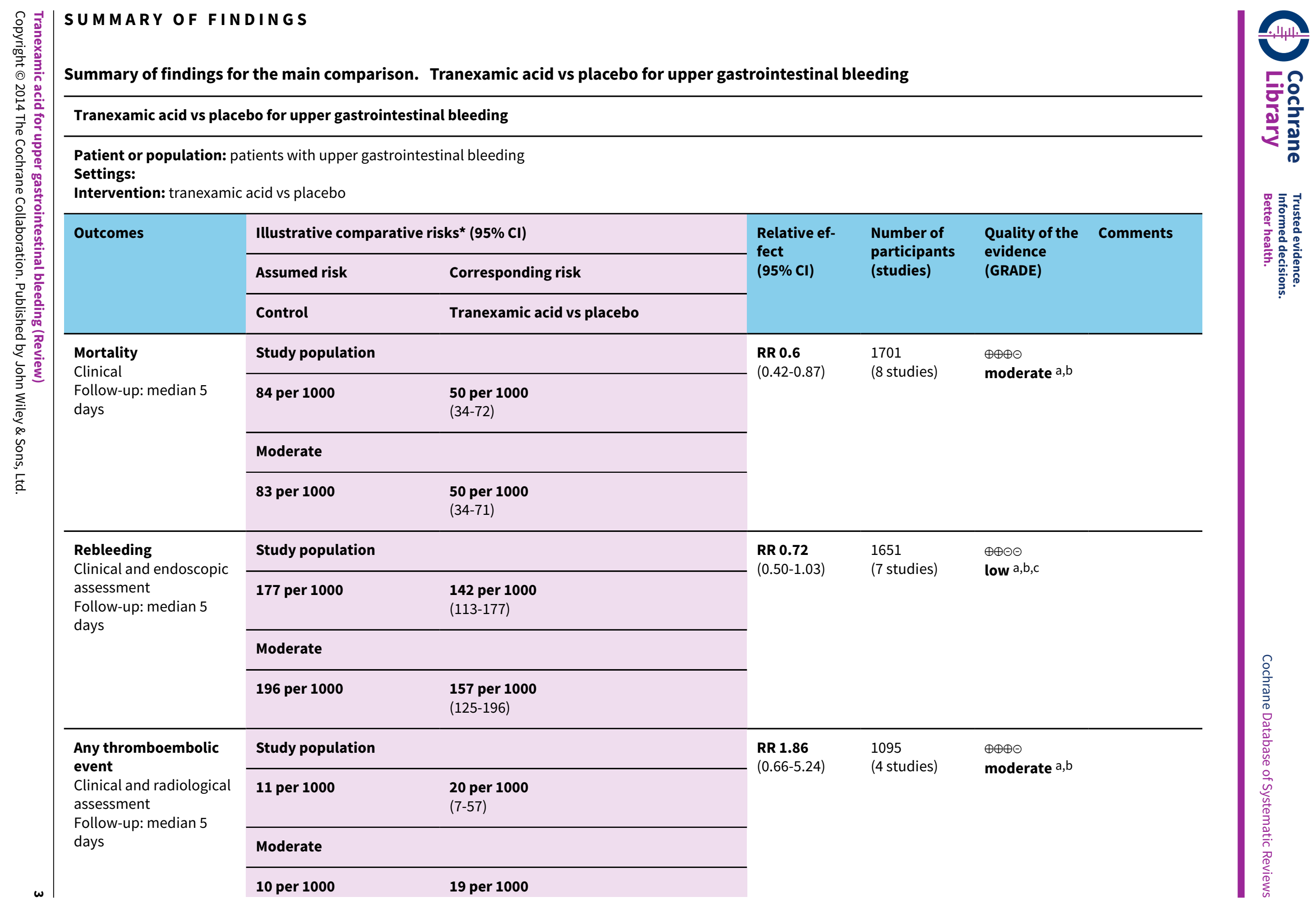




\begin{tabular}{|c|c|c|c|c|c|}
\hline \multirow{5}{*}{ 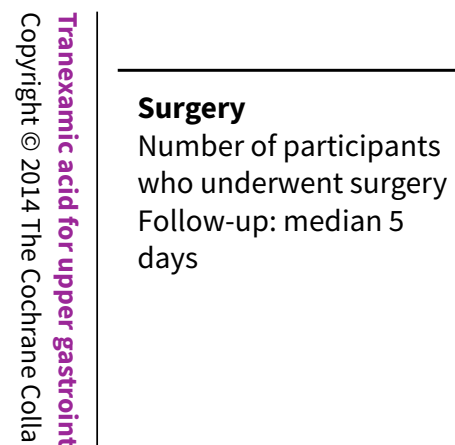 } & \multicolumn{2}{|r|}{$(7-52)$} & \multirow{5}{*}{$\begin{array}{l}\text { RR 0.61 } \\
(0.35-1.04)\end{array}$} & \multirow{5}{*}{$\begin{array}{l}1551 \\
\text { (7 studies) }\end{array}$} & \multirow{5}{*}{$\begin{array}{l}\oplus \oplus \oplus \ominus \\
\text { moderate } a\end{array}$} \\
\hline & \multicolumn{2}{|c|}{ Study population } & & & \\
\hline & 142 per 1000 & $\begin{array}{l}103 \text { per } 1000 \\
(79-135)\end{array}$ & & & \\
\hline & \multicolumn{2}{|l|}{ Moderate } & & & \\
\hline & 154 per 1000 & $\begin{array}{l}\mathbf{1 1 2} \text { per } 1000 \\
(86-146)\end{array}$ & & & \\
\hline \multirow{4}{*}{$\begin{array}{l}\text { Transfusion } \\
\text { Number needing blood } \\
\text { transfusion } \\
\text { Follow-up: median } 3 \\
\text { weeks }\end{array}$} & \multicolumn{2}{|c|}{ Study population } & \multirow{4}{*}{$\begin{array}{l}\text { RR 1.02 } \\
(0.94-1.1)\end{array}$} & \multirow{4}{*}{$\begin{array}{l}931 \\
\text { (5 studies) }\end{array}$} & \multirow{4}{*}{$\begin{array}{l}\oplus \ominus \ominus \ominus \\
\text { very low } a, d\end{array}$} \\
\hline & 564 per 1000 & $\begin{array}{l}558 \text { per } 1000 \\
(507-620)\end{array}$ & & & \\
\hline & \multicolumn{2}{|l|}{ Moderate } & & & \\
\hline & 583 per 1000 & $\begin{array}{l}\mathbf{5 7 7} \text { per } 1000 \\
(525-641)\end{array}$ & & & \\
\hline
\end{tabular}

*The basis for the assumed risk (e.g. median control group risk across studies) is provided in footnotes. The corresponding risk (and its $95 \%$ confidence interval) is based on the assumed risk in the comparison group and the relative effect of the intervention (and its $95 \% \mathrm{Cl}$ ).

Cl: Confidence interval; RR: Risk ratio.

GRADE Working Group grades of evidence.

High quality: Further research is very unlikely to change our confidence in the estimate of effect.

Moderate quality: Further research is likely to have an important impact on our confidence in the estimate of effect and may change the estimate.

Low quality: Further research is very likely to have an important impact on our confidence in the estimate of effect and is likely to change the estimate.

Very low quality: We are very uncertain about the estimate.

a Most trials had high risk of attrition bias.

bNot possible to evaluate because number of trials was limited.

cStatistical between-trial heterogeneity approached $50 \%$.

dThe number of participants who needed transfusion is an indirect measure of bleeding and varies among clinical sites.

\section{Summary of findings 2. Tranexamic acid vs cimetidine or lansoprazole for upper gastrointestinal bleeding}

Tranexamic acid vs cimetidine or lansoprazole for upper gastrointestinal bleeding

Patient or population: patients with upper gastrointestinal bleeding 


\begin{tabular}{|c|c|c|c|c|c|c|}
\hline \multirow{4}{*}{ 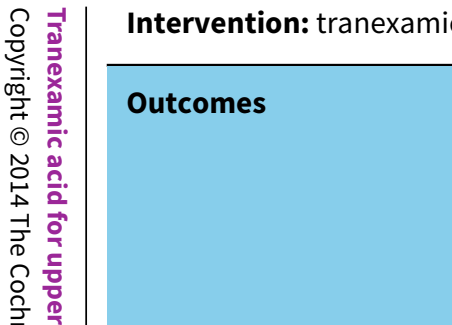 } & acid vs cimetidi & razole & & & & \\
\hline & \multicolumn{2}{|c|}{ Illustrative comparative risks ${ }^{\star}(95 \% \mathrm{Cl})$} & \multirow{3}{*}{$\begin{array}{l}\text { Relative ef- } \\
\text { fect } \\
(95 \% \mathrm{Cl})\end{array}$} & \multirow{3}{*}{$\begin{array}{l}\text { Number of } \\
\text { participants } \\
\text { (studies) }\end{array}$} & \multirow{3}{*}{$\begin{array}{l}\text { Quality of the } \\
\text { evidence } \\
\text { (GRADE) }\end{array}$} & \multirow[t]{3}{*}{ Comments } \\
\hline & Assumed risk & Corresponding risk & & & & \\
\hline & Control & $\begin{array}{l}\text { Tranexamic acid vs cimetidine or lansopra- } \\
\text { zole }\end{array}$ & & & & \\
\hline \multirow{4}{*}{$\begin{array}{l}\text { Mortality } \\
\text { Number of participants } \\
\text { who died } \\
\text { Follow-up: median } 5 \\
\text { days }\end{array}$} & \multicolumn{2}{|c|}{ Study population } & \multirow{4}{*}{$\begin{array}{l}\text { RR 0.91 } \\
(0.50-1.64)\end{array}$} & \multirow{4}{*}{$\begin{array}{l}720 \\
\text { (2 studies) }\end{array}$} & \multirow{4}{*}{$\begin{array}{l}\oplus \oplus \oplus \ominus \\
\text { moderate }\end{array}$} & \\
\hline & 61 per 1000 & $\begin{array}{l}\mathbf{5 6} \text { per } \mathbf{1 0 0 0} \\
(31-101)\end{array}$ & & & & \\
\hline & \multicolumn{2}{|l|}{ Moderate } & & & & \\
\hline & 48 per 1000 & $\begin{array}{l}44 \text { per } 1000 \\
(24-79)\end{array}$ & & & & \\
\hline \multirow{4}{*}{$\begin{array}{l}\text { Rebleeding } \\
\text { Clinical and endoscopic } \\
\text { assessment } \\
\text { Follow-up: median } 5 \\
\text { days }\end{array}$} & \multicolumn{2}{|c|}{ Study population } & \multirow{4}{*}{$\begin{array}{l}\text { RR 0.87 } \\
(0.64-1.2)\end{array}$} & \multirow{4}{*}{$\begin{array}{l}720 \\
\text { (2 studies) }\end{array}$} & \multirow{4}{*}{$\begin{array}{l}\oplus \oplus \oplus \ominus \\
\text { moderate } a, b\end{array}$} & \\
\hline & 188 per 1000 & $\begin{array}{l}\mathbf{1 6 6} \text { per } 1000 \\
(121-226)\end{array}$ & & & & \\
\hline & \multicolumn{2}{|l|}{ Moderate } & & & & \\
\hline & 161 per 1000 & $\begin{array}{l}142 \text { per } 1000 \\
(103-193)\end{array}$ & & & & \\
\hline \multirow{4}{*}{$\begin{array}{l}\text { Surgery } \\
\text { Number of participants } \\
\text { who underwent surgery } \\
\text { Follow-up: median } 5 \\
\text { days }\end{array}$} & \multicolumn{2}{|c|}{ Study population } & \multirow{4}{*}{$\begin{array}{l}\text { RR 0.83 } \\
(0.54-1.26)\end{array}$} & \multirow{4}{*}{$\begin{array}{l}720 \\
\text { (2 studies) }\end{array}$} & \multirow{4}{*}{$\begin{array}{l}\oplus \oplus \oplus \ominus \\
\text { moderate } a, b\end{array}$} & \\
\hline & 139 per 1000 & $\begin{array}{l}115 \text { per } 1000 \\
(79-168)\end{array}$ & & & & \\
\hline & \multicolumn{2}{|l|}{ Moderate } & & & & \\
\hline & 105 per 1000 & $\begin{array}{l}87 \text { per } 1000 \\
(60-127)\end{array}$ & & & & \\
\hline \multirow{2}{*}{$\begin{array}{l}\text { Transfusion } \\
\text { Number of participants } \\
\text { who required at least } 1 \\
\text { blood transfusion } \\
\text { Follow-up: median } 5 \\
\text { days }\end{array}$} & \multicolumn{2}{|c|}{ Study population } & \multirow{2}{*}{$\begin{array}{l}\text { RR 0.97 } \\
(0.78-1.22)\end{array}$} & \multirow{2}{*}{$\begin{array}{l}720 \\
\text { ( } 2 \text { studies) }\end{array}$} & \multirow{2}{*}{$\begin{array}{l}\oplus \oplus \ominus \ominus \\
\text { low } a, b, c\end{array}$} & \\
\hline & 573 per 1000 & $\begin{array}{l}\mathbf{5 7 9} \text { per } 1000 \\
(510-654)\end{array}$ & & & & \\
\hline
\end{tabular}


*The basis for the assumed risk (e.g. median control group risk across studies) is provided in footnotes. The corresponding risk (and its $95 \%$ confidence interval) is based on the assumed risk in the comparison group and the relative effect of the intervention (and its $95 \% \mathrm{Cl}$ ).

Cl: Confidence interval; RR: Risk ratio.

GRADE Working Group grades of evidence.

High quality: Further research is very unlikely to change our confidence in the estimate of effect.

Moderate quality: Further research is likely to have an important impact on our confidence in the estimate of effect and may change the estimate.

Low quality: Further research is very likely to have an important impact on our confidence in the estimate of effect and is likely to change the estimate.

Very low quality: We are very uncertain about the estimate.

a High risk of bias based on assessment of attrition.

bNot possible to evaluate because number of trials was limited.

cThis outcome measure is a surrogate estimate for bleeding. 


\section{B A C K G R O U N D}

\section{Description of the condition}

Upper gastrointestinal bleeding is a common reason for emergency hospital admission and a common complication in hospitalised patients (Rockall 1995; Blatchford 1997). A systematic review of general, population-based epidemiological studies found that the incidence of upper gastrointestinal bleeding among patients treated with non-steroidal anti-inflammatory drugs was 0.8 per 1000 (Hernandez 2002). The risk of upper gastrointestinal bleeding has been found to increase significantly with age, co-morbidity and use of non-steroidal anti-inflammatory drugs (Yavorski 1995; Paspatis 2000; Ng 2006). About 80\% of patients with upper gastrointestinal bleeding will spontaneously stop bleeding, without recurrence (Laine 1994). The highest mortality and morbidity rates are seen in the remaining $20 \%$, who experience recurrent or continued bleeding. Among patients referred to endoscopy for suspected upper gastrointestinal bleeding, 30-day mortality is $10 \%$ to $14 \%$ (van Leerdam 2003; Barkun 2004; Barkun 2010).

\section{Description of the intervention}

Several endoscopic therapies have been found to be effective in clinical trials (Kahi 2005). However, some hospital departments may not have access to acute endoscopy. In other cases, patients may refuse to undergo endoscopy. Identification of drugs that may achieve haemostasis, stabilising patients until endoscopy can be performed, is therefore essential.

\section{How the intervention might work}

Tranexamic acid reduces fibrinolysis by slowing down the conversion of plasminogen to plasmin. The resulting reduction in fibrinolysis prevents the breakdown of blood clots, which may result in haemostasis but increased risk of thromboembolic complications. This drug was introduced for menorrhagia in 1968 (Vermylen 1968) and is used to reduce blood loss during surgery (Laupacis 1997; Cid 2005). A large multi-centre trial found that tranexamic acid reduces mortality in individuals with bleeding trauma by $9 \%$ and results in no apparent increase in thromboembolic events (CRASH-2). It is possible that a similar effect can be achieved in cases of upper gastrointestinal bleeding.

\section{Why it is important to do this review}

Endoscopic therapy and proton pump inhibitors serve as the cornerstone in the treatment of bleeding from peptic ulcers (Lau 2013). These treatments are highlighted in recent evidencebased guidelines (Dworzynski 2012), which do not recommend tranexamic acid for the management of upper gastrointestinal bleeding. Randomised trials have assessed the effects of tranexamic acid among patients with suspected or verified upper gastrointestinal bleeding (Cormack 1973; Biggs 1976; Engquist 1979; Bergqvist 1980; Barer 1983; Holstein 1987; Hawkey 2001). A meta-analysis of these trials revealed that tranexamic acid reduces the risks of rebleeding and mortality (Henry 1989). However, results of individual trials varied considerably. Furthermore, the overall result has been characterised as disproportionately skewed by inclusion of a trial in which mortality in the control group was surprisingly high (Barer 1983; Palmer 2002). We have previously published a systematic review on tranexamic acid versus placebo (Gluud 2008). A randomised trial on tranexamic acid for upper gastrointestinal bleeding was published after our previous meta-analysis had been completed (Bagnenko 2011). This trial was included in a recent review, which determined that we still have insufficient evidence for definitive conclusions (Manno 2014). We performed this updated systematic review on tranexamic acid versus placebo, cimetidine or lansoprazole for upper gastrointestinal bleeding.

\section{OBJECTIVES}

To assess the effects of tranexamic acid versus no intervention, placebo or other antiulcer drugs for upper gastrointestinal bleeding.

\section{METHODS}

\section{Criteria for considering studies for this review}

\section{Types of studies}

Randomised trials, irrespective of language, blinding, length of follow-up or publication status.

\section{Types of participants}

Individuals with suspected or endoscopically verified upper gastrointestinal bleeding, irrespective of the bleeding source.

\section{Types of interventions}

Primary analyses included trials on tranexamic acid versus placebo or no intervention. Secondary analyses compared tranexamic acid versus any other antiulcer drug.

\section{Types of outcome measures}

\section{Primary outcomes}

- Mortality.

- Adverse events. We defined serious adverse events as all adverse events considered serious by study participants or investigators.

\section{Secondary outcomes}

- Rebleeding.

- Surgery.

\section{Search methods for identification of studies}

\section{Electronic searches}

Electronic searches of the following were performed July 2014.

- Cochrane Central Register of Controlled Trials (CENTRAL) (Appendix 1).

- MEDLINE via Ovid SP (Appendix 2).

- EMBASE via Ovid SP (Appendix 3).

- Science Citation Index Expanded (Appendix 4).

\section{Searching other resources}

We scanned conference proceedings and reference lists from relevant trials, wrote to authors of included trials and searched the International Clinical Trials Registry Platform (ICTRP) to identify trials on tranexamic acid (Appendix 5). 


\section{Data collection and analysis}

\section{Selection of studies}

Three review authors (LLG, SLK and CB) screened search results for potentially eligible trials and identified trials that were eligible for inclusion. Excluded trials were listed together with the reasons for exclusion. At each stage of the selection process, at least two review authors independently reviewed search results and selected trials for inclusion. Three review authors (LLG, SLK and CB) agreed on the final list.

\section{Data extraction and management}

Two review authors (LLG and SLK) independently extracted data using data collection forms designed to capture information specific to this review. CB verified the extracted data at this update. Disagreements were resolved through discussion before analyses were performed. Data on baseline participant characteristics (inclusion criteria, mean age, proportion of men and source of bleeding), dose and duration of treatment, country of origin, publication status, funding, duration of follow-up and risk of bias were gathered from the included trials and from correspondence with study authors. For trials published in Russian, two review authors (LLG and CB) extracted data obtained by machine translation (Google translate). Dimitrinka Nikolova from the Cochrane Hepato-Biliary Group read the original Russian language publication and verified the extracted data.

\section{Assessment of risk of bias in included studies}

At least two review authors (LLG and SLK or CB) independently assessed risk of bias in the included studies by using the risk of bias assessment tool provided in Chapter 8 of theCochrane Handbook for Systematic Reviews of Interventions (Higgins 2011). We compared these evaluations and discussed and resolved inconsistencies.

We rated the following domains separately for each of the included studies as 'low risk of bias,' 'high risk of bias' or 'unclear risk of bias' if the risk of bias was uncertain or unknown. These assessments are reported in the 'Risk of bias' table for each individual study included in the Characteristics of included studies section of the review.

- Allocation sequence was adequately generated ('sequence generation').

- Allocation was adequately concealed ('allocation concealment').

- Knowledge of allocated interventions was adequately prevented during the study ('blinding') (whether the trial was described as double-blind or single-blind, and whether blinding involved healthcare providers, outcome assessors or those performing data extraction or data analysis).

- Incomplete outcome data were adequately addressed.

- Reports of the study were free of suggestions of selective outcome reporting (whether clinically relevant outcome measures were defined and reported).

- The study was apparently free of other sources of bias that could put it at high risk of bias (e.g. potential conflicts of interest, pharmaceutical funding/support, or both).

- Other biases (sample size calculations and registration in clinical trial databases).
We categorised and reported the overall risk of bias of each of the included studies according to the following.

- Low risk of bias (plausible bias unlikely to seriously alter the results) if all criteria were met.

- Unclear risk of bias (plausible bias that raises some doubt about the results) if one or more criteria were assessed as unclear.

- High risk of bias (plausible bias that seriously weakens confidence in the results) if one or more criteria were not met.

We reported these assessments in the Risk of bias in included studies section of this review.

\section{Measures of treatment effect}

The effect measure consisted of risk ratios (RRs) with 95\% confidence intervals (Cls).

\section{Unit of analysis issues}

As the primary outcome measure was mortality, only trials using a parallel-group design were included. Data on all intervention groups were analysed separately for all trials, including those with more than two parallel arms. Risk of selection bias was noted in the allocation of participants to intervention or control groups and in the administration of collateral interventions; therefore we did not include cluster-randomised trials.

\section{Multi-armed trials}

For trials with multiple intervention groups, we partitioned participants into individual allocation arms to perform pair-wise comparisons. For example, a three-arm trial with 30 participants (10 in each arm) allocated to tranexamic acid versus placebo versus antiulcer drugs would allow two pair-wise comparisons of tranexamic acid versus placebo (10 vs 10 participants) and tranexamic acid versus antiulcer drugs (10 vs 10 participants).

\section{Dealing with missing data}

We contacted study investigators to request data on all randomly assigned participants to perform intention-to-treat analyses. We used simple imputation to evaluate the potential influence of missing data: imputing failures, imputing successes and worst- and best-case scenarios (Higgins 2008).

\section{Assessment of heterogeneity}

We assessed clinical heterogeneity by examining trial conditions on the basis of characteristics of included trials, participants and interventions. We assessed statistical heterogeneity by using 12 statistical values and reported heterogeneity as important when the $I^{2}$ statistic was $>60 \%$ (Higgins 2011).

\section{Assessment of reporting biases}

We attempted to obtain trial protocols to compare reported outcome measures in the protocol versus those in the published trial. For analyses with at least 10 trials, we planned to assess reporting biases and other dissemination biases by using funnel plots (Higgins 2011) and to perform regression analyses by using Harbord's modified test (Harbord 2006). Our analyses included only eight trials; therefore we did not carry out a statistical analysis of reporting bias. 


\section{Data synthesis}

We performed analyses in RevMan 2014 (The Nordic Cochrane Centre, Copenhagen, Denmark), STATA version 13 (Stata Corp., Texas, USA) and Trial Sequential Analysis (The Cochrane HepatoBiliary Group, Copenhagen, Denmark). We performed all metaanalyses using both random-effects and fixed-effect models. Fixedeffect model meta-analyses are reported only when the results of the two models differ (e.g. one model shows no difference between interventions and the other shows an intervention effect).

We report the results of analyses with the total number of participants. When it was possible to calculate an effect size, we report this with 95\% confidence intervals. When the calculated effect size was statistically significant (defined as $P$ value $<0.05$ ), we state whether the result favoured the intervention or control condition.

\section{Subgroup analysis and investigation of heterogeneity}

We performed separate analyses of trials on tranexamic acid versus placebo or no intervention and trials on tranexamic acid versus antiulcer drugs, as well as subgroup analyses of trials with low risk of bias based on assessment of the separate domains. We also analysed subgroups of trials that used endoscopic therapy and trials published in English or Russian.

\section{Sensitivity analysis}

We performed two further analyses to determine the effects of missing outcome data and a per-protocol analysis to evaluate the influence of missing data. In the first scenario, all participants in the intervention arm with missing outcome data were included as treatment failures and participants in the control group with missing outcome data were considered as treatment successes. In the per-protocol analyses, we excluded participants with missing outcome data. We performed a post hoc analysis that excluded a trial with a very high event rate in the control group (Barer 1983).

\section{Trial sequential analysis}

We performed a post hoc trial sequential analysis to determine the risk of bias associated with cumulative testing and to evaluate futility in the assessment of mortality and bleeding (Higgins 2008; Wetterslev 2008). We performed the analysis with power set to $80 \%$, alpha to $5 \%$ and model-based diversity and with relative risk reduction (RRR) to $30 \%$. We set the control incidence to $10 \%$ for the analysis of mortality and to $30 \%$ for the analysis of bleeding.

\section{'Summary of findings' tables}

We prepared a 'Summary of findings' table (Guyatt 2008) using GRADEpro software (Gradepro 3.6) and we included information on the results of our primary outcomes in relation to risk of heterogeneity, duration of follow-up and quality of the evidence.

\section{RE S U L T S}

\section{Description of studies}

\section{Results of the search}

The original electronic searches identified 84 hits, and the updated search 37 hits (Appendix 6). The manual search identified one additional record. After reading the titles and abstracts, we retrieved 15 records for further assessment. One record referred to an ongoing trial (ISRCTN11225767) on tranexamic acid for gastrointestinal bleeding (Characteristics of ongoing studies). We will include this trial in future updates if the results become available (Figure 1). We excluded four records that did not assess tranexamic acid for upper gastrointestinal bleeding. In total, we included eight randomised controlled trials in our analyses (Cormack 1973; Biggs 1976; Engquist 1979; Bergqvist 1980; Barer 1983; Holstein 1987; Hawkey 2001; Bagnenko 2011). We received additional information about study design and outcomes from the primary investigators of one of the included trials (Hawkey 2001). For the remaining trials, we had access only to published data. The included trials were published as full paper articles, from 1973 to 2011. One trial was published in Russian (Bagnenko 2011), and the remaining in English. 
Figure 1. Study flow diagram.

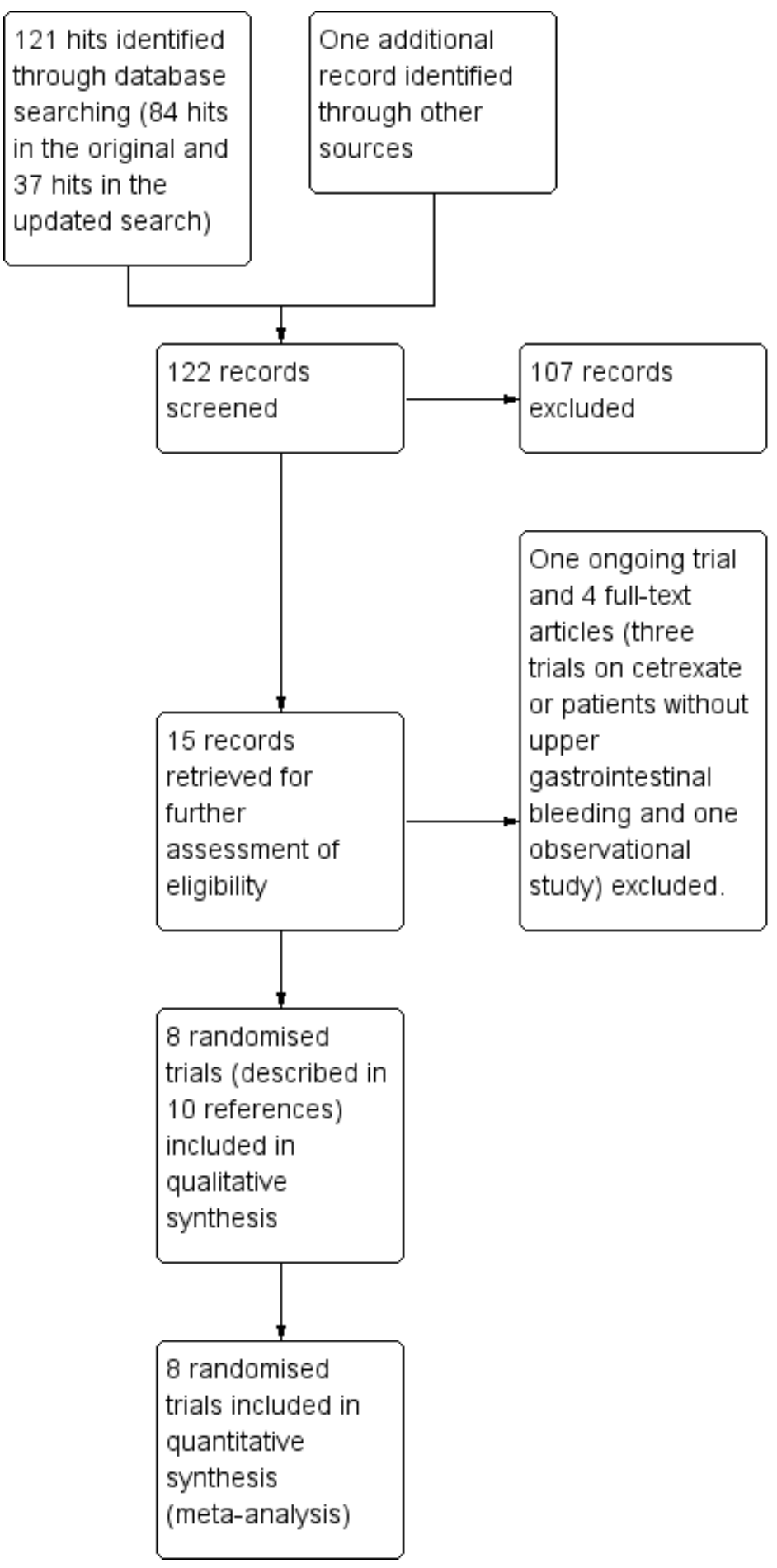

\section{Included studies}

\section{Design}

All trials were randomised, parallel arm. One trial was open (Bagnenko 2011), and the remaining trials were double blind with a placebo control.

\section{Sample sizes}

The numbers of participants randomly assigned ranged from 47 to 216 (median 204).

\section{Setting}

All trials were performed at hospitals. 


\section{Participants}

The trials included participants admitted with suspected upper gastrointestinal bleeding confirmed by endoscopy or clinically through gastric lavage, hematemesis or melena. Participants with previous or ongoing thromboembolic disease or renal disease and pregnant women were excluded from the trials. Three trials included only participants with severe bleeding (Engquist 1979; Bergqvist 1980; Bagnenko 2011). In the remaining trials, proportions of participants with circulatory involvement ranged from $1 \%$ to $21 \%$. Mean participant age ranged from 56 to 62 years in the tranexamic acid groups and from 56 to 65 years in the control groups. Five trials reported that a proportion of participants had oesophageal varices (mean proportion $8 \%$, range $5 \%$ to $16 \%$ ). In four trials (Barer 1983; Holstein 1987; Hawkey 2001; Bagnenko 2011), participants underwent endoscopy within 24 hours after admission. One trial reported that $12 \%$ of included participants did not undergo the planned endoscopy. Two trials evaluated participants with endoscopy but did not specify the time frame (Engquist 1979; Bergqvist 1980). The remaining two trials did not include an endoscopic evaluation (Cormack 1973) or had access to endoscopy only during a portion of the trial (Biggs 1976).

\section{Interventions}

Tranexamic acid was administered intravenously in one trial (Barer 1983) and orally in three trials (Cormack 1973; Bergqvist 1980; Hawkey 2001). The remaining trials used intravenous followed by oral administration. The total daily dose of tranexamic acid ranged from 4 to $8 \mathrm{~g}$. Duration of therapy ranged from two to seven days.

\section{Comparisons}

One trial included a no intervention control group (Bagnenko 2011), and the remaining trials included a placebo control. Two trials were multi-armed and included control groups randomly assigned to the histamine receptor $(\mathrm{H} 2)$ agonist cimetidine (Barer
1983) or the proton pump inhibitor lansoprazole alone or with tranexamic acid (Hawkey 2001). One trial allowed co-intervention with the histamine receptor agonist famotidine (Bagnenko 2011). In five trials, a variety of co-interventions, including novaluzide and cimetidine or ranitidine, were administered to participants in both treatment arms (Cormack 1973; Biggs 1976; Engquist 1979; Bergqvist 1980; Holstein 1987). Two trials used endoscopic therapy to control bleeding (Hawkey 2001; Bagnenko 2011).

\section{Outcomes}

One trial reported endoscopically verified rebleeding (Bagnenko 2011). Another trial reported rebleeding as assessed by hematemesis, melena or hypotension plus a drop in haemoglobin or rebleeding seen at endoscopy (Hawkey 2001). Two trials defined rebleeding on the basis of a drop in haemoglobin (Holstein 1987) or a drop in haemoglobin, hematemesis or melena (Barer 1983). The remaining trials did not define rebleeding.

\section{Excluded studies}

We excluded four trials that were published as full paper articles (Hollanders 1982; Tam 1989; Adachi 2001; Sabovic 2003). These trials were excluded because they were observational, assessed certrexate or did not include participants with upper gastrointestinal bleeding (Excluded studies).

\section{Risk of bias in included studies}

\section{Allocation}

One trial (Bagnenko 2011) reported an adequate method for allocation sequence generation (Figure 2). The remaining trials did not describe how the allocation sequence was generated. One trial did not describe how allocation was concealed (Bagnenko 2011). In the remaining trials, allocation was adequately concealed through double-blind administration of the intervention or placebo. 
Figure 2. Risk of bias summary: review authors' judgements about each risk of bias item for each included study.

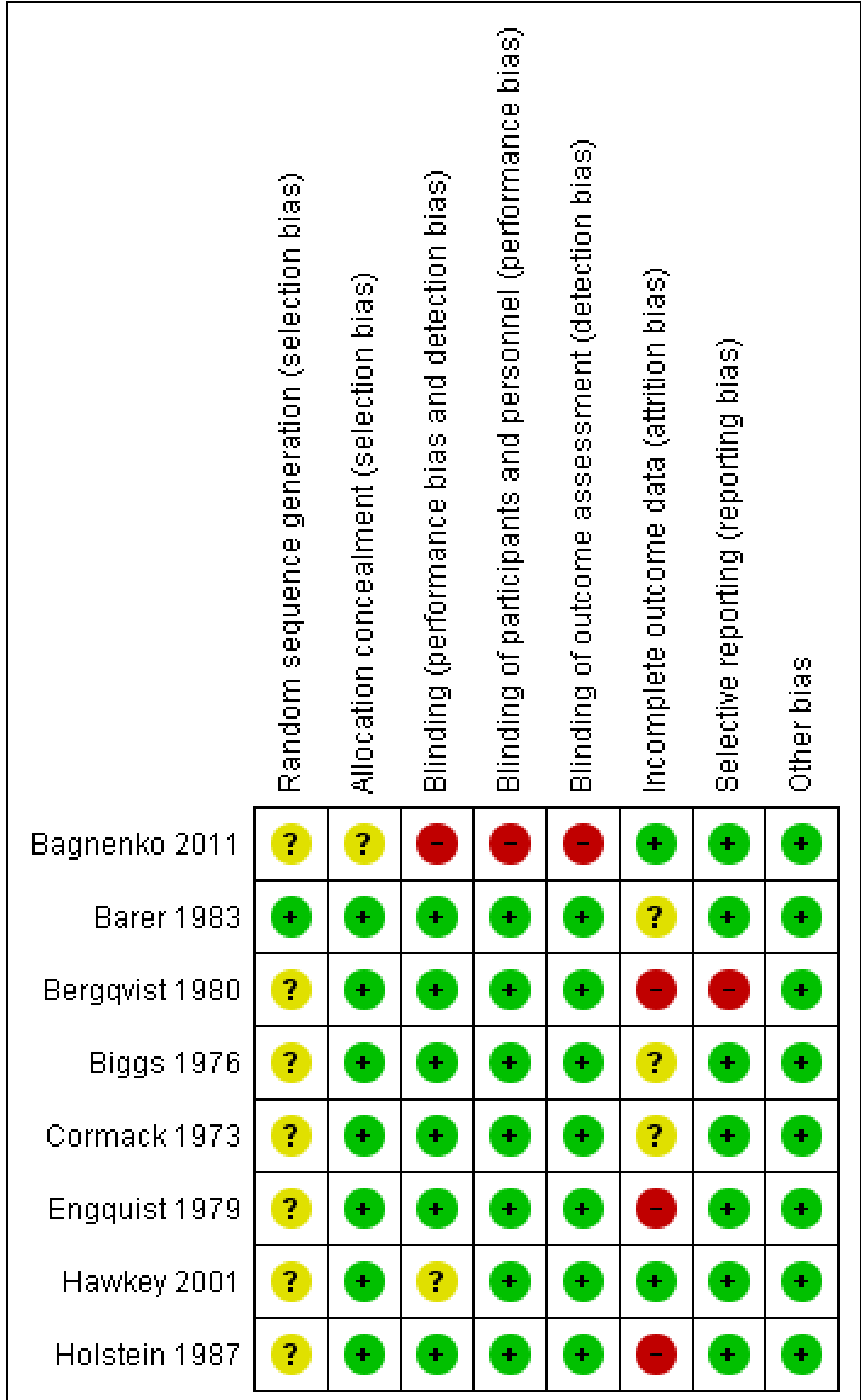

\section{Blinding}

One trial was open (Bagnenko 2011). The remaining trials were double blind with a placebo control.
Incomplete outcome data

Attrition was one of the main sources of bias. Five trials reported losses to follow-up (Engquist 1979; Bergqvist 1980; Barer 1983; Holstein 1987; Hawkey 2001). Three trials gave the impression 
that no dropouts or withdrawals had occurred, although this was not specifically reported (Cormack 1973; Biggs 1976; Bagnenko 2011). One in five participants $(20 \%)$ were withdrawn or excluded after randomisation. Reasons for exclusion included lack of verified bleeding, malignant disease and terminal illness, or the treatment was administered too late.

\section{Selective reporting}

One trial did not report bleeding and was classed as having high risk of reporting bias (Bergqvist 1980).

\section{Other potential sources of bias}

None of the trials had other potential sources of bias.

\section{Effects of interventions}

See: Summary of findings for the main comparison Tranexamic acid vs placebo for upper gastrointestinal bleeding; Summary of findings 2 Tranexamic acid vs cimetidine or lansoprazole for upper gastrointestinal bleeding

\section{Comparison 1. Tranexamic acid versus placebo \\ Primary outcomes}

\section{Mortality}

All trials reported mortality (Analysis 1.1). Forty-two of 851 participants randomly assigned to tranexamic acid and 71 of 850 in the control group died. The fixed-effect meta-analysis showed that tranexamic acid reduced mortality (RR $0.60,95 \% \mathrm{Cl} 0.42$ to 0.87 ; P value 0.007$)$. No statistical heterogeneity was noted between trials $\left(I^{2}=0 \%\right)$.

\section{Sensitivity analyses and trial sequential analysis}

The analysis was not confirmed in a scenario analysis in which all participants with missing outcome data were included as treatment failures (Analysis 1.2), but it was confirmed in a perprotocol analysis (data not shown).

Analyses of studies with low risk of bias confirmed that attrition was the main source of bias (Analysis 1.3). The single remaining trial with low risk of attrition bias (Hawkey 2001) found no effects of the intervention. A similar result was seen when trials that used endoscopic therapy to control bleeding were analysed (Analysis 1.4). No difference (test for subgroup differences $P$ value 0.67 ) was noted between trials published in English and those translated from Russian (Analysis 1.5).

One of the trials has been criticised for reporting a high control group event rate (Barer 1983; Palmer 2002). This trial included 516 participants and reported a large weight in the analysis (49\%). In a post hoc analysis that excluded this trial, tranexamic acid was seen to have no effect on mortality (RR $0.73,95 \% \mathrm{Cl} 0.45$ to 1.19 ; analysis not shown). In our post hoc trial sequential analysis (Figure 3 ), the required information size was not met, suggesting that the metaanalysis is inconclusive. 
Figure 3. Trial sequential analysis of eight trials on tranexamic acid versus placebo or no intervention. Outcome measure is mortality. Analysis was performed with alpha $5 \%$ and power $80 \%$. Model-based heterogeneity correction was $0 \%$, relative risk reduction $30 \%$ and control group incidence $10 \%$. Graph shows the Z-curve, which is the cumulative result of analysis with trials added according to year of publication. Horizontal line represents 'traditional' $5 \%$ level of significance, and inward sloping red line shows trial sequential monitoring boundary. Vertical line represents required information size. Analysis shows that the Z-curve crosses the trial sequential monitoring boundary, suggesting that the result of the meta-analysis is confirmed when analysis is adjusted for cumulative testing. Total number of included participants $(N=1701)$ is only $62 \%$ of required information size $(\mathrm{N}=2714)$. The meta-analysis therefore remains inconclusive.

Monitoring is a Two-sided graph

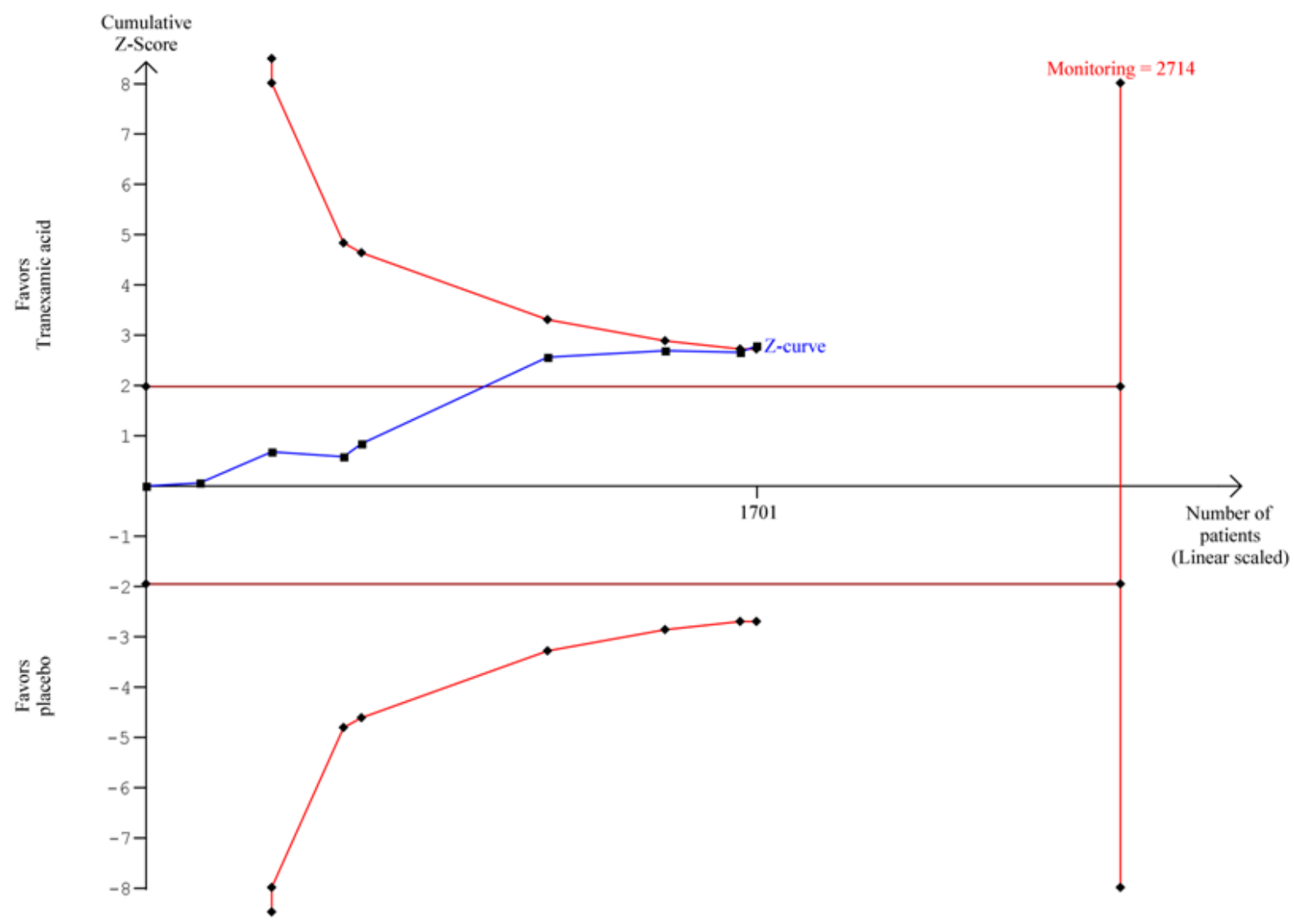

Bleeding

Seven trials reported rebleeding (Analysis 1.6). In total, rebleeding was diagnosed for 117 of 826 participants in the tranexamic acid group and for 146 of 825 participants in the control group.

\section{Sensitivity analyses and trial sequential analysis}

The difference was not statistically significant (RR $0.72,95 \% \mathrm{Cl} 0.50$ to 1.03 ; $P$ value 0.07 ). A similar conclusion was reached in worst- case scenario analysis (Analysis 1.7) and per-protocol analysis (data not shown). Analyses of trials with low risk of bias found no effects of tranexamic acid on bleeding (Analysis 1.8), and no differences were noted between trials stratified according to use of endoscopic therapy (Analysis 1.9) or language (Analysis 1.10). In the trial sequential analysis (Figure 4), 95\% of the required information size was reached. This analysis suggested that the meta-analysis was inconclusive. 
Figure 4. Trial sequential analysis of seven trials on tranexamic acid versus placebo or no intervention. Outcome measure is bleeding. Analysis was performed with alpha $5 \%$ and power $\mathbf{8 0} \%$. Model-based heterogeneity correction was $53 \%$, relative risk reduction $30 \%$ and control group incidence $10 \%$. Graph shows the Z-curve, which is the cumulative result of analysis with trials added according to year of publication. Horizontal line represents 'traditional' 5\% level of significance, and inward sloping red line shows trial sequential monitoring boundary. Vertical line represents required information size. Analysis shows that the Z-curve does not cross the trial sequential monitoring boundary, and the total number of participants $(\mathrm{N}=1651)$ is $95 \%$ of required information size $(\mathrm{N}=1734)$. The meta-analysis therefore remains inconclusive.

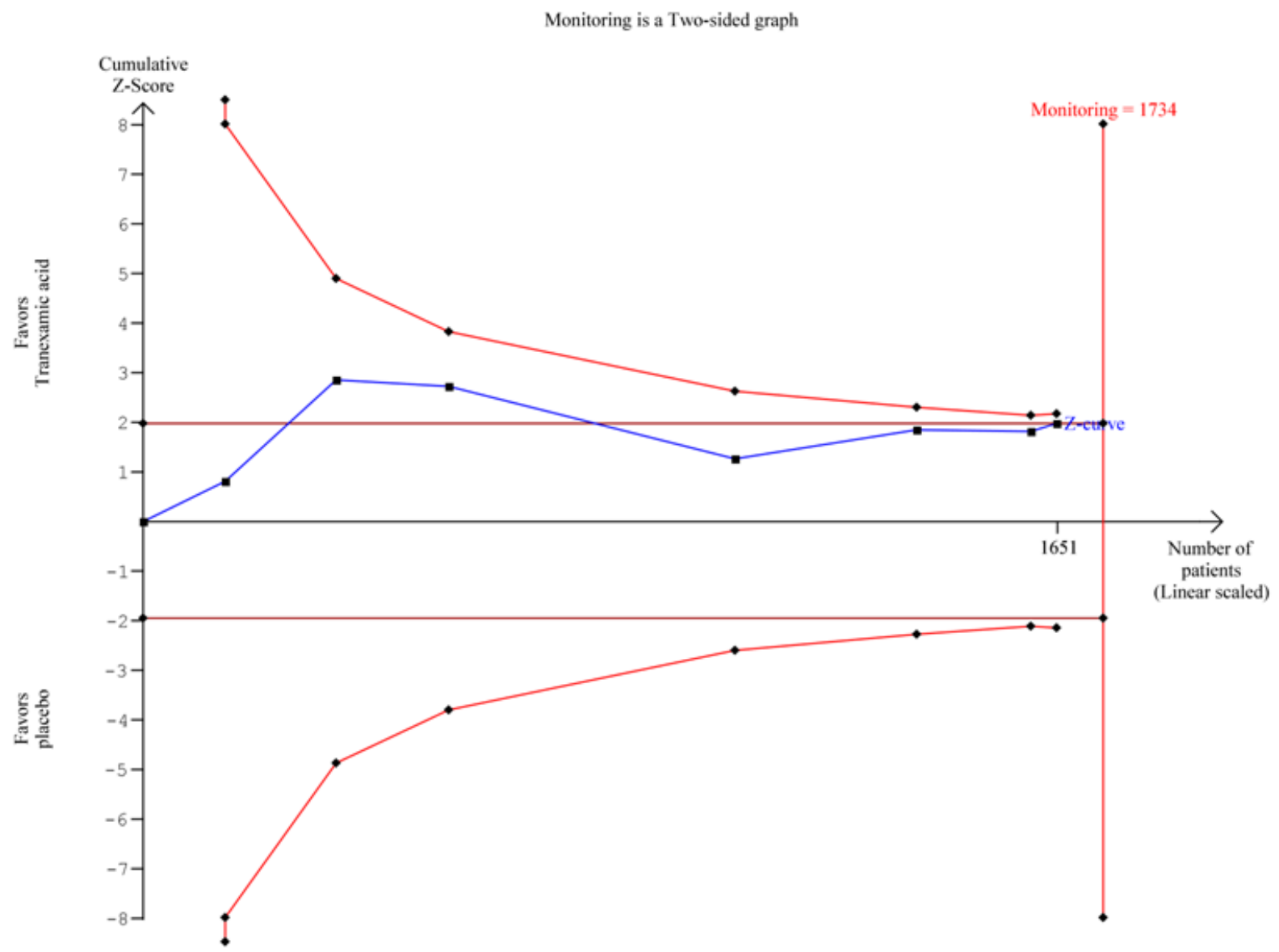

\section{Adverse events}

Several participants randomly assigned to tranexamic acid experienced abdominal pain, nausea, vomiting and thrombophlebitis at the injection site (Table 1). We were unable to perform meta-analyses on these adverse events because data were not provided for both treatment and control groups.

Three trials (Analysis 1.13) on 1048 participants reported thromboembolic events (Engquist 1979; Barer 1983; Holstein 1987). Among participants randomly assigned to tranexamic acid, two cases of myocardial infarction, two cases of pulmonary embolism and one case of cerebral infarction occurred. In the placebo group, two cases of myocardial infarction and two cases of cerebral infarction were recorded. When data on these serious thromboembolic events were combined, the difference was not statistically significant (RR 1.37, 95\% Cl 0.36 to 5.28; Analysis 1.11). Six cases of deep venous thrombosis occurred among participants randomly assigned to tranexamic acid compared with two cases in the placebo group (RR 2.32, 95\% Cl 0.60 to 8.89; Analysis 1.12). The numbers of participants with any thrombotic event were not significantly different between treatment and control groups (RR 1.86, $95 \% \mathrm{Cl} 0.66$ to 5.24; Analysis 1.13).

\section{Secondary outcomes}

\section{Surgery}

Seven studies with 1551 participants reported the numbers of participants who required surgery (Analysis 1.14). Between-trial heterogeneity was important $\left(1^{2}=63 \%\right)$. Tranexamic acid appeared to reduce the risk of surgery in a fixed-effect meta-analysis (RR $0.73,95 \% \mathrm{Cl} 0.56$ to 0.95$)$, but this result was no longer statistically significant at the $5 \%$ level, when a random-effects meta-analysis was used (RR 0.61, 95\% Cl 0.35 to 1.04; Analysis 1.14). 


\section{Transfusions}

We planned to analyse the transfusion requirements of included participants, but we did not identify the necessary data. We therefore performed a post hoc analysis of the total numbers of participants who needed at least one blood transfusion (Analysis 1.15) and found no apparent differences between tranexamic acid and placebo (RR 1.02, 95\% Cl 0.94 to 1.11 in 931 participants; five studies; $\left.\left.\right|^{2}=0 \%\right)$.

\section{Comparison 2. Tranexamic acid versus antiulcer drugs (cimetidine or lansoprazole)}

\section{Primary outcomes}

\section{Mortality and rebleeding}

Two trials compared tranexamic acid with cimetidine (Barer 1983) or lansoprazole (Hawkey 2001). These trials found no significant effects of tranexamic acid on mortality (RR $0.91,95 \% \mathrm{Cl} 0.50$ to 1.64 ; 720 participants; $I^{2}=0 \%$; Analysis 2.1 ) or bleeding (RR $0.87,95 \% \mathrm{Cl}$ 0.64 to $1.20 ; I^{2}=0 \%$; Analysis 2.2 ).

\section{Adverse events}

We were unable to perform meta-analyses on adverse events (Table 1). Barer 1983 reported one case of fatal stroke in the tranexamic acid group and two cases of confusion in the control group. Hawkey 2001 reported no adverse events in the tranexamic acid or control groups.

\section{Surgery and transfusions}

Trials comparing tranexamic acid versus cimetidine or lansoprazole (Barer 1983; Hawkey 2001) found no differences between allocation groups regarding the need for surgery (RR $0.83,95 \% \mathrm{Cl} 0.54$ to 1.26; 720 participants; two studies; $I^{2}=3 \%$; Analysis 2.3 ) or blood transfusion (RR $0.97,95 \% \mathrm{Cl} 0.78$ to $1.22 ; 720$ participants; two studies; $I^{2}=64 \%$; Analysis 2.4 ).

\section{'Summary of findings' tables}

As shown in the 'Summary of findings' tables on tranexamic acid versus placebo (Summary of findings for the main comparison) or cimetidine or lansoprazole (Summary of findings 2), the quality of the evidence was downgraded to moderate or low because of risk of bias.

\section{DISCUSSION}

\section{Summary of main results}

This review includes eight randomised controlled trials and a total of 1701 participants with acute upper gastrointestinal bleeding. The meta-analyses found that tranexamic acid appears to have a beneficial effect on mortality, but a high dropout rate in some trials means that we cannot be sure of this until additional research is published. Reduced mortality did not clearly reflect reduced bleeding or surgery. The result of the primary meta-analysis was not stable in analyses that adjusted for risk of attrition bias or in trial sequential analyses. When trials with high risk of attrition bias were removed, only one trial was left (Hawkey 2001) in the analysis, so although we may need to be cautious about the potential effects of dropouts, the evidence is still fairly strong in favour of tranexamic acid. Likewise, only two of the included trials used endoscopic therapy (Hawkey 2001; Bagnenko 2011). These trials found no clear effects of tranexamic acid on bleeding was noted and that attrition bias may affect the assessment of mortality, therefore the combined evidence does not allow any recommendations to be made. Additional randomised controlled trials are needed to determine the effects of tranexamic acid. A large randomised double-blind trial on tranexamic acid for gastrointestinal bleeding is ongoing (ISRCTN11225767). This trial has started to randomly assign the first participants. Results of this trial are expected to finally confirm or refute the effects of tranexamic acid for individuals with upper gastrointestinal bleeding.

\section{Overall completeness and applicability of evidence}

During recent years, standard care and assessment of outcomes have changed considerably (Dworzynski 2012). Previously, patients were not offered full diagnostic endoscopy or endoscopic interventions that are used as standard care today. It is noteworthy that the trial that is the most favourable towards tranexamic acid was published in 1983 (Barer 1983). The clinical question today is not whether tranexamic acid is better than placebo, but whether tranexamic acid is better than or may be used in combination with current treatments. One of the included trials found no significant difference between tranexamic acid and lansoprazole when used alone, or when the two treatments were combined (Hawkey 2001). This trial was not designed to assess clinical outcomes, and its statistical power may well have been too small to detect clinically relevant effects. On the other hand, this trial does suggest that additional research is necessary.

Several reasons may explain why we found that tranexamic acid reduces mortality but not bleeding. One possible explanation is that tranexamic acid may be effective in subgroups of patients with a serious prognosis. One of the included trials assessed the influence of the severity of bleeding on the intervention effect (Hawkey 2001). This trial included 414 participants with suspected upper gastrointestinal bleeding and asked admitting investigators to classify participant risk as high or low on the basis of their presentation. No specific criteria were used. Overall, high-risk participants were more likely to die or need surgery. The effect of tranexamic acid was not related to risk stratification.

\section{Quality of the evidence}

In clinical guidelines on the management of upper gastrointestinal non-variceal bleeding, tranexamic acid may be considered, but it is not recommended as routine therapy (Palmer 2002; Barkun 2003). This treatment generally is not recommended for variceal bleeding, and in several trials, participants with varices were excluded after randomisation. However, meta-analyses in the present review include participants with upper gastrointestinal bleeding due to oesophageal varices. No significant association was found between treatment effect and the proportion of participants with varices. These analyses are only hypothesis generating but suggest that the effects of tranexamic acid on mortality may also be seen in this patient group. Likewise, we found no significant differences between trials in which participants received tranexamic acid in a daily dose of $12 \mathrm{~g}$ for two days and those in which the dose was $4 \mathrm{~g}$ for seven days. It may be interesting to determine whether dose or treatment duration is related to the risk of thromboembolic events, but we did not have sufficient data to analyse this question.

Vested interests were reported in some of the included trials. We were unable to identify specific design features that introduced bias due to vested interests and the fact that we included only eight 
trials limited the possibility of further analyses. Nevertheless, we cannot exclude that this factor can lead to bias. On the other hand, the trial that received full funding (Hawkey 2001) found no effect of tranexamic acid on any of the outcomes assessed.The largest trials received tranexamic acid and placebo from pharmaceutical companies (Barer 1983; Hawkey 2001). The trial with the most positive assessment of tranexamic acid received only medications (Barer 1983).

Mortality is an outcome measure that is relatively stable in relation to performance and ascertainment bias, but not to attrition bias. We found that attrition was the main source of bias. Included trials randomly assigned participants early, and many excluded participants after the source of bleeding had been identified by endoscopy. Exclusion of participants appeared to be done before blinding was broken, although this is not specifically stated. As the result of risk of bias and clinical heterogeneity between trials, which is inevitable given that trials were conducted over several decades, the overall quality of the evidence was deemed moderate or low (Summary of findings for the main comparison; Summary of findings 2).

\section{Potential biases in the review process}

Potential biases in the review process are limited. In particular, we attempted to avoid bias in identification and selection of trials, but one possible limitation is that despite exhaustive searching, it is possible that other trials have been conducted, and although we searched extensively, we did not identify unpublished trials or trials published in abstract form. We included only one paper that was published in Russian (Bagnenko 2011). Remaining trials were published in English. Because the number of identified trials was limited, we were not able to analyse the risk of publication bias. In theory, meta-analyses are observational, which may lead to biases. A written protocol is necessary to determine biases in the review process and in general, the original protocol must be followed. However, we made methodological changes to our protocol that were based on recent evidence and guidelines (Guyatt 2008; Higgins 2008; Higgins 2011). These changes were mainly related to assessment of risk of bias. We also performed post hoc sequential analyses to improve assessment of biases.

\section{Agreements and disagreements with other studies or reviews}

Although our review methods did include assessment of all reported adverse events, we did not carry out a separate search for adverse effects; therefore one of the most important limitations of the present review is the fact that information about adverse events was limited. The recent debate on the use of antifibrinolytic drugs highlights the need for valid safety data. In 2006, an observational study of patients undergoing revascularisation was reported (Mangano 2006). This study included 1295 participants who received aprotinin and 822 who received tranexamic acid. Multivariable analyses found that aprotinin, but not tranexamic acid, significantly increased the risk of renal failure and cardiovascular or cerebral adverse events. Although results support the safety of tranexamic acid, the participant cohort was considerably different from that included in the present review. In particular, the trials included in the present review excluded participants with previous thromboembolic or renal disease. Therefore, it may be argued that one of the most important limitations of the present review is that limited information about adverse events was available. Although we found no significant association between tranexamic acid and risk of thromboembolic events, our analyses did not have sufficient statistical power to allow clear inferences. Theoretically, tranexamic acid increases the risk of thrombosis due to unopposed fibrin generation. Case reports have associated tranexamic acid with thromboembolic events, which may be fatal (Rydin 1976; Agnelli 1982; Endo 1988; Woo 1989; Taparia 2002). The trials in the present review excluded participants with previous thromboembolic events, although this is not generally accepted as a contraindication in clinical practice. Likewise these trials excluded participants with renal disease. One observational study has assessed the effects of tranexamic acid on patients undergoing dialysis. Tranexamic acid seems relatively safe to use in this patient group. However, the study included only 20 participants, so additional evidence is needed (Sabovic 2003).

\section{AUTHORS' CONCLUSIONS}

\section{Implications for practice}

This review found no evidence to support or refute the use of tranexamic acid for upper gastrointestinal bleeding, in terms of mortality, bleeding, surgery or transfusion requirements. We found limited information about adverse events. At present, tranexamic acid cannot be recommended for routine clinical practice.

\section{Implications for research}

This review found no evidence that tranexamic acid offers benefit to patients with upper gastrointestinal bleeding in terms of mortality, bleeding, surgery or requirement for blood transfusion. At the time of this update in 2014, additional large pragmatic randomised trials seem warranted. We are aware of one large study (8000 participants) that is in progress, so this review will be much more informative in a few years. However, proton pump inhibitors and endoscopic interventions for severe gastrointestinal bleeding, including injection and thermal and mechanical methods such as haemoclips, may serve as alternative effective interventions (Dworzynski 2012).

Further examination of the efficacy and safety of tranexamic acid would involve high-quality randomised controlled trials. The timing of randomisation is essential in avoiding attrition bias and limiting the number of withdrawals. The trial may use a pragmatic design and include all participants with suspected bleeding based on haemoglobin levels, gastric lavage, hematemesis or melena. Alternatively, only participants with endoscopically verified bleeding may be randomly assigned. The pragmatic approach could mean inclusion of participants with concomitant disease who may have higher risk of bleeding. When such participants are excluded from trials, we may overestimate benefits and underestimate adverse events. Therefore the advantage of a pragmatic approach would be that investigators could assess whether the intervention works in these patients, that is, such trials would have high external validity.

Future trials should assess tranexamic acid delivered orally or intravenously over an appropriate length of time. The trials included in this review assessed a daily dose of up to 16 to $42 \mathrm{~g}$. A placebo arm (for comparison with tranexamic acid) should be included, and interventions should be administered in accordance with current treatment recommendations. Accordingly, cointerventions such as proton pump inhibitors and endoscopic 
therapy must be offered. Assessment of outcome measures should be clearly defined, and reports of adverse events should be included. Endoscopic examination with appropriate control of severe bleeding should be included, and endoscopic verification of clinically significant rebleeding should be performed. In addition, clinical measures of rebleeding should be included. Other important outcome measures include mortality (30-day or in-hospital), along with need for emergency surgery, blood transfusion and adverse events (major or minor).

\section{ACKNOWLEDGEMENTS}

We would like to thank Dr GM Hawkey (Hawkey 2001), who responded to our request for additional data and Dimitrinka Nikolova of the Cochrane Hepato-Biliary Group for translations. 


\section{REFERE N C E S}

\section{References to studies included in this review}

\section{Bagnenko 2011 \{published data only\}}

Bagnenko SF, Verbitskii VG. [Antifibrinolitic therapy for the treatment of massive ulcerative gastro-intestinal bleedings]. Khirurgiia 2011;4:42-6. [PUBMED: 21721282]

\section{Barer 1983 \{published data only\}}

* Barer D, Ogilvie A, Henry D, Dronfield M, Coggon D, French S, et al. Cimetidine and tranexamic acid in the treatment of acute upper-gastrointestinal-tract bleeding. New England Journal of Medicine 1983;308:1571-5.

Ogilvie AL, Barer D, Dronfield MW. Trial of cimetidine, tranexamic acid and placebo in the management of acute upper gastrointestinal haemorrhage [abstract]. Gut 1981;22:F20.

\section{Bergqvist 1980 \{published data only\}}

Bergqvist D, Dahlgren S, Hessman Y. Local inhibition of the fibrinolytic system in patients with massive upper gastrointestinal hemorrhage. Uppsala Journal of Medical Sciences 1980;85:173-8.

\section{Biggs 1976 \{published data only\}}

Biggs JC, Hugh TB, Dodds AJ. Tranexamic acid and upper gastrointestinal haemorrhage - a double-blind trial. Gut 1976;17:729-34.

\section{Cormack 1973 \{published data only\}}

Cormack F, Chakrabarti RR, Jouhar AJ, Fearnley GR.

Tranexamic acid in upper gastrointestinal haemorrhage. Lancet 1973;1:1207-8.

\section{Engquist 1979 \{published data only\}}

Engqvist A, Brostrom O, von Feilitzen F, Halldin M, Nystrom B, Ost A, et al. Tranexamic acid in massive haemorrhage from the upper gastrointestinal tract: a double-blind study. Scandinavian Journal of Gastroenterology 1979;14:839-44.

Hawkey 2001 \{published data only\} Hawkey GM, Cole AT, McIntyre AS, Long RG, Hawkey CJ. Drug treatments in upper gastrointestinal bleeding: value of endoscopic findings as surrogate end points. Gut 2001;49:372-9.

\section{Holstein 1987 \{published data only\}}

* von Holstein CC, Eriksson SB, Kallen R. Tranexamic acid as an aid to reducing blood transfusion requirements in gastric and duodenal bleeding. BMJ (Clinical Research Edition) 1987;294:7-10

von Holstein CC, Eriksson SB, Kallen R. Tranexamic acid in gastric and duodenal bleeding. Scandinavian Journal of Gastroenterology. Supplement 1987;137:71-4.

\section{References to studies excluded from this review}

\section{Adachi 2001 \{published data only\}}

Adachi K, Suetsugu H, Moriyama N, Kazumori H, Kawamura A, Fujishiro $\mathrm{H}$, et al. Influence of Helicobacter pylori infection and cetraxate on gastric mucosal blood flow during healing of endoscopic mucosal resection-induced ulcers. Journal of Gastroenterology and Hepatology 2001;16:1211-6.

Hollanders 1982 \{published data only\}

Hollanders D, Thomson JM, Schofield PF. Tranexamic acid therapy in ulcerative colitis. Postgraduate Medical Journal 1982;58(676):87-91.

\section{Sabovic 2003 \{published data only\}}

Sabovic M, Lavre J, Vujkovac B. Tranexamic acid is beneficial as adjunctive therapy in treating major upper gastrointestinal bleeding in dialysis patients. Nephrology, Dialysis, Transplantation 2003;18:1388-91.

Tam 1989 \{published data only\}

Tam HC, Lee YC, Wong HY, Ng NS. Healing of gastric ulcer in the elderly: a double-blind study of cetraxate versus ranitidine. Journal of Clinical Gastroenterology 1989;11:183-6.

\section{References to ongoing studies \\ ISRCTN11225767 \{unpublished data only\}}

Tranexamic acid for the treatment of gastrointestinal haemorrhage: an international randomised, double blind placebo controlled trial. ISRCTN 2012.

\section{Additional references}

\section{Agnelli 1982}

Agnelli G, Gresele P, De Cunto M, Gallai V, Nenci GG. Tranexamic acid, intrauterine contraceptive devices and fatal cerebral arterial thrombosis. Case report. British Journal of Obstetrics and Gynaecology 1982;89:681-2.

\section{Barkun 2003}

Barkun A, Bardou M, Marshall JK, Nonvariceal Upper GI Bleeding Consensus Conference Group. Consensus recommendations for managing patients with nonvariceal upper gastrointestinal bleeding. Annals of Internal Medicine 2003;139:843-57.

\section{Barkun 2004}

Barkun A, Sabbah S, Enns R, Armstrong D, Gregor J, Fedorak RN, et al. The Canadian Registry on Nonvariceal Upper Gastrointestinal Bleeding and Endoscopy (RUGBE): Endoscopic hemostasis and proton pump inhibition are associated with improved outcomes in a real-life setting. The American Journal of Gastroenterology 2004;99(7):1238-46. [PUBMED: 15233660]

\section{Barkun 2010}

Barkun AN, Bardou M, Kuipers EJ, Sung J, Hunt RH, Martel M, Sinclair P, International Consensus Upper Gastrointestinal Bleeding Conference Group. International consensus recommendations on the management of patients with nonvariceal upper gastrointestinal bleeding. Annals of Internal Medicine 2010;152:101-13. 


\section{Blatchford 1997}

Blatchford O, Davidson LA, Murray WR, Blatchford M, Pell J. Acute upper gastrointestinal haemorrhage in west of Scotland: case ascertainment study. BMJ (Clinical Research Edition) 1997;315:510-4.

\section{Cid 2005}

Cid J, Lozano M. Tranexamic acid reduces allogeneic red cell transfusions in patients undergoing total knee arthroplasty: results of a meta-analysis of randomized controlled trials. Transfusion 2005;45:1302-7.

\section{CRASH-2}

CRASH-2 Collaborators. Effect of tranexamic acid in traumatic brain injury: a nested randomised, placebo controlled trial (CRASH-2 Intracranial Bleeding Study). BMJ (Clinical Research Edition) 2011;343:d3795. [PUBMED: 21724564]

\section{Dworzynski 2012}

Dworzynski K, Pollit V, Kelsey A, Higgins B, Palmer K. Management of acute upper gastrointestinal bleeding: summary of NICE guidance. BMJ (Clinical Research Edition) 2012;344:e3412. [PUBMED: 22695897]

\section{Endo 1988}

Endo Y, Nishimura S, Miura A. Deep-vein thrombosis induced by tranexamic acid in idiopathic thrombocytopenic purpura. JAMA 1988;259:3561-2.

\section{Gradepro 3.6 [Computer program]}

The Grading of Recommendations Assessment, Development and Evaluation (GRADE) Working Group. GRADEpro. [Computer program]. Version 3.2 for Windows. Jan Brozek, Andrew Oxman, Holger Schünemann, 2008. The Grading of Recommendations Assessment, Development and Evaluation (GRADE) Working Group, 2008.

\section{Guyatt 2008}

Guyatt GH, Oxman AD, Vist GE, Kunz R, Falck-Ytter Y, AlonsoCoello $P$, et al. GRADE: an emerging consensus on rating quality of evidence and strength of recommendations. BMJ (Clinical Research Edition) 2008;336(7650):924-6. [PUBMED: 18436948]

\section{Harbord 2006}

Harbord RM, Egger M, Sterne JA. A modified test for smallstudy effects in meta-analyses of controlled trials with binary endpoints. Statistics in Medicine 2006;25(20):3443-57. [PUBMED: 16345038]

\section{Henry 1989}

Henry DA, O'Connell DL. Effects of fibrinolytic inhibitors on mortality from upper gastrointestinal haemorrhage. BMJ (Clinical Research Edition) 1989;298:1142-6.

\section{Hernandez 2002}

Hernandez-Diaz S, Rodriguez LA. Incidence of serious upper gastrointestinal bleeding/perforation in the general population: review of epidemiologic studies. Journal of Clinical Epidemiology 2002;55:157-63.

\section{Higgins 2008}

Higgins JPT, Green S (editors). Cochrane Handbook for Systematic Reviews of Interventions Version 5.0.0 [updated February 2008]. The Cochrane Colloboration, 2008. www.cochrane-handbook.org.

\section{Higgins 2011}

Higgins JPT, Green S (editors). Cochrane Handbook for Systematic Reviews of Interventions Version 5.1.0 [updated March 2011]. The Cochrane Collaboration, 2011. www.cochranehandbook.org.

\section{Kahi 2005}

Kahi CJ, Jensen DM, Sung JJ, Bleau BL, Jung HK, Eckert G, et al. Endoscopic therapy versus medical therapy for bleeding peptic ulcer with adherent clot: a meta-analysis. Gastroenterology 2005;129:855-62.

\section{Laine 1994}

Laine L, Peterson WL. Bleeding peptic ulcer. New England Journal of Medicine 1994;331(11):717-27. [PUBMED: 8058080]

\section{Lau 2013}

Lau JY, Barkun A, Fan DM, Kuipers EJ, Yang YS, Chan FK. Challenges in the management of acute peptic ulcer bleeding. Lancet 2013;381(9882):2033-43. [PUBMED: 23746903]

\section{Laupacis 1997}

Laupacis A, Fergusson D. Drugs to minimize perioperative blood loss in cardiac surgery: meta-analyses using perioperative blood transfusion as the outcome. The International Study of Peri-operative Transfusion (ISPOT) Investigators. Anesthesia and Analgesia 1997;85:1258-67.

\section{Mangano 2006}

Mangano DT, Tudor IC, Dietzel C. The risk associated with aprotinin in cardiac surgery. The New England Journal of Medicine 2006;354:353-65.

\section{Manno 2014}

Manno D, Ker K, Roberts I. How effective is tranexamic acid for acute gastrointestinal bleeding?. BMJ (Clinical Research Edition) 2014;348:g1421. [PUBMED: 24535627]

\section{Ng 2006}

$\mathrm{Ng}$ W, Wong WM, Chen WH, Tse HF, Lee PY, Lai KC, et al. Incidence and predictors of upper gastrointestinal bleeding in patients receiving low-dose aspirin for secondary prevention of cardiovascular events in patients with coronary artery disease. World Journal of Gastroenterology 2006;12:2923-7.

\section{Palmer 2002}

Palmer KR. Non-variceal upper gastrointestinal haemorrhage: guidelines. Gut 2002;Suppl 4:1-6.

\section{Paspatis 2000}

Paspatis GA, Matrella E, Kapsoritakis A, Leontithis C, Papanikolaou N, Chlouverakis GJ, et al. An epidemiological study of acute upper gastrointestinal bleeding in Crete, Greece. European Journal of Gastroenterology \& Hepatology 2000;12:1215-20. 


\section{RevMan 2014 [Computer program]}

The Nordic Cochrane Centre, The Cochrane Collaboration. Review Manager (RevMan). Version Version 5.3. Copenhagen: The Nordic Cochrane Centre, The Cochrane Collaboration, 2014.

\section{Rockall 1995}

Rockall TA, Logan RF, Devlin HB, Northfield TC. Incidence of and mortality from acute upper gastrointestinal haemorrhage in the United Kingdom. Steering Committee and members of the National Audit of Acute Upper Gastrointestinal Haemorrhage. BMJ (Clinical Research Edition) 1995;311:222-6.

\section{Rydin 1976}

Rydin E, Lundberg PO. Tranexamic acid and intracranial thrombosis. Lancet 1976;2:49.

\section{Taparia 2002}

Taparia M, Cordingley FT, Leahy MF. Pulmonary embolism associated with tranexamic acid in severe acquired haemophilia. European Journal of Haematology 2002;68:307-9.

\section{van Leerdam 2003}

van Leerdam ME, Vreeburg EM, Rauws EA, Geraedts AA, Tijssen JG, Reitsma JB, et al. Acute upper GI bleeding: did anything change? Time trend analysis of incidence and outcome of acute upper GI bleeding between 1993/1994 and 2000. The American Journal of Gastroenterology 2003;98(7):1494-9. [PUBMED: 12873568]

\section{Vermylen 1968}

Vermylen J, Verhaegen-Declercq ML, Fierens F, Verstraete M. A double blind study of the effect of tranexamic acid in essential menorrhagia. Bulletin de la Société Royale Belge de Gynécologie et D'Obstétrique 1968;38:385-90.

\section{Wetterslev 2008}

Wetterslev J, Thorlund K, Brok J, Gluud C. Trial sequential analysis may establish when firm evidence is reached in cumulative meta-analysis. Journal of Clinical Epidemiology 2008;61:64-75.

\section{Woo 1989}

Woo KS, Tse LK, Woo JL, Vallance-Owen J. Massive pulmonary thromboembolism after tranexamic acid antifibrinolytic therapy. British Journal of Clinical Practice 1989;43:465-6.

\section{Yavorski 1995}

Yavorski RT, Wong RK, Maydonovitch C, Battin LS, Furnia A, Amundson DE. Analysis of 3,294 cases of upper gastrointestinal bleeding in military medical facilities. American Journal of Gastroenterology 1995;90:568-73.

\section{References to other published versions of this review Gluud 2008 \\ Gluud LL, Klingenberg SL, Langholz E. Systematic review: tranexamic acid for upper gastrointestinal bleeding. Alimentary Pharmacology and Therapeutics 2008;27:752-8.}

* Indicates the major publication for the study

\section{CHARACTERISTICS OF STUDIES}

Characteristics of included studies [ordered by study ID]

Bagnenko 2011

\begin{tabular}{ll}
\hline Methods & Randomised trial on tranexamic acid vs no intervention \\
\hline Participants & Inclusion criteria: patients admitted with endoscopically verified severe upper gastrointestinal bleed- \\
ing & Number of participants randomly assigned: 47 \\
Mean age tranexamic acid/control: $62 / 64$ years \\
Proportion: \\
- of men: $62 \%$ \\
- with peptic ulcer: $100 \%$ \\
- with oesophageal varices: $0 \%$ \\
- with massive bleeding: $100 \%$
\end{tabular}

\begin{tabular}{ll}
\hline Interventions & Tranexamic acid $10 \mathrm{mg} / \mathrm{kg}$ IV or oral 3 times/d vs no intervention \\
\hline Outcomes & All-cause mortality, rebleeding and surgery \\
\hline Endoscopy & Performed within 24 hours of admission \\
\hline Definition of re-bleeding & Endoscopically verified bleeding \\
\hline \hline
\end{tabular}


Bagnenko 2011 (Continued)

\begin{tabular}{ll} 
Duration of therapy & 3 days \\
\hline Notes & No funding reported
\end{tabular}

\section{Risk of bias}

\begin{tabular}{|c|c|c|}
\hline Bias & Authors' judgement & Support for judgement \\
\hline $\begin{array}{l}\text { Random sequence genera- } \\
\text { tion (selection bias) }\end{array}$ & Unclear risk & Not described \\
\hline $\begin{array}{l}\text { Allocation concealment } \\
\text { (selection bias) }\end{array}$ & Unclear risk & Not described \\
\hline $\begin{array}{l}\text { Blinding (performance } \\
\text { bias and detection bias) } \\
\text { All outcomes }\end{array}$ & High risk & Open \\
\hline $\begin{array}{l}\text { Blinding of participants } \\
\text { and personnel (perfor- } \\
\text { mance bias) } \\
\text { All outcomes }\end{array}$ & High risk & Open \\
\hline $\begin{array}{l}\text { Blinding of outcome as- } \\
\text { sessment (detection bias) } \\
\text { All outcomes }\end{array}$ & High risk & Open \\
\hline $\begin{array}{l}\text { Incomplete outcome data } \\
\text { (attrition bias) } \\
\text { All outcomes }\end{array}$ & Low risk & No losses to follow-up \\
\hline $\begin{array}{l}\text { Selective reporting (re- } \\
\text { porting bias) }\end{array}$ & Low risk & Mortality and bleeding are reported \\
\hline Other bias & Low risk & No other apparent biases are reported \\
\hline
\end{tabular}

Barer 1983

\begin{tabular}{|c|c|}
\hline Methods & Randomised trial on tranexamic acid vs cimetidine vs placebo \\
\hline \multirow[t]{7}{*}{ Participants } & $\begin{array}{l}\text { Inclusion criteria: patients admitted with upper gastrointestinal bleeding confirmed by observation of } \\
\text { haematemesis or melena } \\
\text { Number of participants randomly assigned: } 516\end{array}$ \\
\hline & Mean age: $60-63$ years \\
\hline & Proportion: \\
\hline & - of men: $65 \%$ \\
\hline & - with peptic ulcer: $58 \%$ \\
\hline & - with oesophageal varices: $5 \%$ \\
\hline & - with massive bleeding: $13 \%$ \\
\hline Interventions & $\begin{array}{l}\text { Tranexamic acid } 1 \mathrm{~g} \text { IV } 4 \text { times/d then } 1 \mathrm{~g} \text { orally } 4 \text { times/d vs cimetidine } 400 \mathrm{mg} \text { IV } 4 \text { times/d then } 400 \\
\text { mg orally } 4 \text { times/d vs placebo }\end{array}$ \\
\hline
\end{tabular}


Barer 1983 (Continued)

\begin{tabular}{ll} 
Outcomes & All-cause mortality, rebleeding, surgery and adverse events \\
\hline Endoscopy & Performed within 24 hours of admission \\
\hline Definition of re-bleeding & $\begin{array}{l}\text { Severe hematemesis or fresh melena or a fall in haemoglobin of at least 2 } \mathrm{g} / \mathrm{dL} \text { within } 24 \text { hours after the } \\
\text { first day of admission }\end{array}$ \\
\hline Duration of therapy & 7 days \\
\hline Notes & Kabi Vitrum Ltd and Smith Kline and French supplied medications; details of funding not supplied
\end{tabular}

\section{Risk of bias}

\begin{tabular}{|c|c|c|}
\hline Bias & Authors' judgement & Support for judgement \\
\hline $\begin{array}{l}\text { Random sequence genera- } \\
\text { tion (selection bias) }\end{array}$ & Low risk & Allocation sequence based on random numbers \\
\hline $\begin{array}{l}\text { Allocation concealment } \\
\text { (selection bias) }\end{array}$ & Low risk & Central packaging of coded drug containers \\
\hline $\begin{array}{l}\text { Blinding (performance } \\
\text { bias and detection bias) } \\
\text { All outcomes }\end{array}$ & Low risk & Double blinding (using placebo) \\
\hline $\begin{array}{l}\text { Blinding of participants } \\
\text { and personnel (perfor- } \\
\text { mance bias) } \\
\text { All outcomes }\end{array}$ & Low risk & Participants and personnel blinded (using placebo) \\
\hline $\begin{array}{l}\text { Blinding of outcome as- } \\
\text { sessment (detection bias) } \\
\text { All outcomes }\end{array}$ & Low risk & Outcomes assessed in a blinded manner (using placebo) \\
\hline $\begin{array}{l}\text { Incomplete outcome data } \\
\text { (attrition bias) } \\
\text { All outcomes }\end{array}$ & Unclear risk & $\begin{array}{l}\text { In total, } 99 \text { participants were excluded after randomisation. Reporting of fol- } \\
\text { low-up and handling of missing outcome data are clear }\end{array}$ \\
\hline $\begin{array}{l}\text { Selective reporting (re- } \\
\text { porting bias) }\end{array}$ & Low risk & Mortality and bleeding are reported \\
\hline Other bias & Low risk & No other apparent biases are reported \\
\hline
\end{tabular}

\section{Bergqvist 1980}

\begin{tabular}{ll}
\hline Methods & Randomised trial on tranexamic acid vs placebo \\
\hline Participants & $\begin{array}{l}\text { Inclusion criteria: patients admitted with massive upper gastrointestinal bleeding confirmed by hae- } \\
\text { matemesis or melena and circulatory involvement (criteria not specified) } \\
\text { Number of participants randomly assigned: } 50 \\
\text { Mean age tranexamic acid/placebo: } 61 / 58 \text { years } \\
\text { Proportion: } \\
\text { - of men: } 79 \% \\
\text { - with peptic ulcer: } 65 \%\end{array}$ \\
\hline
\end{tabular}


Bergqvist 1980 (Continued)

- with oesophageal varices: $7 \%$

- with massive bleeding: not reported

\begin{tabular}{ll}
\hline Interventions & Tranexamic acid 2 g orally 6 times daily vs placebo \\
\hline Outcomes & All-cause mortality and surgery \\
\hline Endoscopy & Performed after admission (time frame not specified) \\
\hline Definition of re-bleeding & Not described \\
\hline Duration of therapy & 2 days \\
\hline Notes & No funding reported
\end{tabular}

\section{Risk of bias}

\begin{tabular}{lll}
\hline Bias & Authors' judgement & Support for judgement \\
\hline $\begin{array}{l}\text { Random sequence genera- } \\
\text { tion (selection bias) }\end{array}$ & Unclear risk & Not described \\
\hline
\end{tabular}

\begin{tabular}{lll}
\hline $\begin{array}{l}\text { Allocation concealment } \\
\text { (selection bias) }\end{array}$ & Low risk & Blinded administration of tranexamic acid or placebo \\
\hline $\begin{array}{l}\text { Blinding (performance } \\
\text { bias and detection bias) } \\
\text { All outcomes }\end{array}$ & Low risk & Double-blind placebo-controlled trial \\
\hline $\begin{array}{l}\text { Blinding of participants } \\
\begin{array}{l}\text { and personnel (perfor- } \\
\text { mance bias) }\end{array}\end{array}$ & Low risk & Participants and personnel blinded (using placebo) \\
All outcomes &
\end{tabular}

Blinding of outcome as- $\quad$ Low risk Outcomes assessed in a blinded manner (using placebo)
sessment (detection bias)
All outcomes

\begin{tabular}{|c|c|c|}
\hline $\begin{array}{l}\text { Incomplete outcome data } \\
\text { (attrition bias) }\end{array}$ & High risk & $\begin{array}{l}\text { Outcomes for participants who were excluded or withdrawn from treatment } \\
(14 \%) \text { are not reported }\end{array}$ \\
\hline
\end{tabular}

\begin{tabular}{lll}
\hline $\begin{array}{l}\text { Selective reporting (re- } \\
\text { porting bias) }\end{array}$ & High risk & Continued bleeding or rebleeding is not reported \\
\hline Other bias & Low risk & No other apparent biases are reported \\
\hline
\end{tabular}

\section{Biggs 1976}

\begin{tabular}{ll}
\hline Methods & Randomised trial comparing tranexamic acid vs placebo \\
\hline Participants & $\begin{array}{l}\text { Inclusion criteria: patients admitted with upper gastrointestinal bleeding observed by medical officer } \\
\text { or confirmed by gastric lavage or observation of melena } \\
\text { Number of participants randomly assigned: } 200 \\
\text { Mean age: not reported }\end{array}$
\end{tabular}


Biggs 1976 (Continued)

\section{Proportion:}

- of men: $78 \%$

- with peptic ulcer: $54 \%$

- with oesophageal varices: $6 \%$

- with massive bleeding: $21 \%$

\begin{tabular}{ll}
\hline Interventions & Tranexamic acid $1 \mathrm{~g}$ IV and $1 \mathrm{~g}$ orally 4 times/d then $1 \mathrm{~g}$ orally 4 times/d vs placebo \\
\hline Outcomes & All-cause mortality, rebleeding, surgery and adverse events \\
\hline Endoscopy & $\begin{array}{l}\text { Some participants were evaluated with full endoscopy (time frame and number not specified). Early in } \\
\text { the trial, endoscopy was unavailable }\end{array}$ \\
\hline Definition of re-bleeding & Not described \\
\hline Duration of therapy & 5 days \\
\hline Notes & Funding from Fauldings Australia Ltd \\
\hline
\end{tabular}

\section{Risk of bias}

\begin{tabular}{|c|c|c|}
\hline Bias & Authors' judgement & Support for judgement \\
\hline $\begin{array}{l}\text { Random sequence genera- } \\
\text { tion (selection bias) }\end{array}$ & Unclear risk & Not described \\
\hline $\begin{array}{l}\text { Allocation concealment } \\
\text { (selection bias) }\end{array}$ & Low risk & Blinded administration of tranexamic acid or placebo \\
\hline $\begin{array}{l}\text { Blinding (performance } \\
\text { bias and detection bias) } \\
\text { All outcomes }\end{array}$ & Low risk & Double blinding (using placebo) \\
\hline $\begin{array}{l}\text { Blinding of participants } \\
\text { and personnel (perfor- } \\
\text { mance bias) } \\
\text { All outcomes }\end{array}$ & Low risk & Participants and personnel blinded (using placebo) \\
\hline $\begin{array}{l}\text { Blinding of outcome as- } \\
\text { sessment (detection bias) } \\
\text { All outcomes }\end{array}$ & Low risk & Outcomes assessed in a blinded manner (using placebo) \\
\hline $\begin{array}{l}\text { Incomplete outcome data } \\
\text { (attrition bias) } \\
\text { All outcomes }\end{array}$ & Unclear risk & No withdrawals or exclusions are reported \\
\hline $\begin{array}{l}\text { Selective reporting (re- } \\
\text { porting bias) }\end{array}$ & Low risk & Mortality and bleeding are reported \\
\hline Other bias & Low risk & No other apparent biases are reported \\
\hline
\end{tabular}

\section{Cormack 1973}

\begin{tabular}{ll}
\hline Methods & Randomised trial comparing tranexamic acid vs placebo \\
\hline
\end{tabular}


Cormack 1973 (Continued)

Participants
Inclusion criteria: patients admitted with upper gastrointestinal bleeding confirmed by haematemesis or melena

Number of participants randomly assigned: 150

Mean age: not reported

Proportion of:

- men: $67 \%$

- with peptic ulcer: not reported

- with oesophageal varices: not reported

- with massive bleeding: $11 \%$

\begin{tabular}{ll}
\hline Interventions & Tranexamic acid 1.5 g orally 4 times/d vs placebo \\
\hline Outcomes & All-cause mortality. Continued bleeding, rebleeding and surgery reported only as a composite outcome \\
\hline Endoscopy & Not performed \\
\hline Definition of re-bleeding & Not defined \\
\hline Duration of therapy & 7 days \\
\hline Notes & Funding from AB Kabi, Stockholm, Sweden
\end{tabular}

\section{Risk of bias}

\begin{tabular}{|c|c|c|}
\hline Bias & Authors' judgement & Support for judgement \\
\hline $\begin{array}{l}\text { Random sequence genera- } \\
\text { tion (selection bias) }\end{array}$ & Unclear risk & Not described \\
\hline $\begin{array}{l}\text { Allocation concealment } \\
\text { (selection bias) }\end{array}$ & Low risk & Blinded administration of tranexamic acid or placebo \\
\hline $\begin{array}{l}\text { Blinding (performance } \\
\text { bias and detection bias) } \\
\text { All outcomes }\end{array}$ & Low risk & Double blinding (using placebo) \\
\hline $\begin{array}{l}\text { Blinding of participants } \\
\text { and personnel (perfor- } \\
\text { mance bias) } \\
\text { All outcomes }\end{array}$ & Low risk & Participants and personnel blinded (using placebo) \\
\hline $\begin{array}{l}\text { Blinding of outcome as- } \\
\text { sessment (detection bias) } \\
\text { All outcomes }\end{array}$ & Low risk & Outcomes assessed in a blinded manner (using placebo) \\
\hline $\begin{array}{l}\text { Incomplete outcome data } \\
\text { (attrition bias) } \\
\text { All outcomes }\end{array}$ & Unclear risk & No withdrawals or dropouts are reported \\
\hline $\begin{array}{l}\text { Selective reporting (re- } \\
\text { porting bias) }\end{array}$ & Low risk & Mortality and bleeding are reported \\
\hline Other bias & Low risk & No other apparent biases are reported \\
\hline
\end{tabular}


Engquist 1979

\begin{tabular}{|c|c|}
\hline Methods & Randomised trial comparing tranexamic acid vs placebo \\
\hline \multirow[t]{6}{*}{ Participants } & $\begin{array}{l}\text { Inclusion criteria: patients admitted with massive upper gastrointestinal bleeding defined as circulato- } \\
\text { ry embarrassment, loss of } 1800 \mathrm{~mL} \text { blood ( } 4 \text { blood units), or haemoglobin concentration lowered by at } \\
\text { least } 30 \mathrm{~g} / \mathrm{L} \\
\text { Number of participants randomly assigned: } 204\end{array}$ \\
\hline & $\begin{array}{l}\text { Mean age tranexamic acid/placebo: } 59 / 56 \text { years } \\
\text { Proportion: }\end{array}$ \\
\hline & - of men: $78 \%$ \\
\hline & - with peptic ulcer: $47 \%$ \\
\hline & - with oesophageal varices: $16 \%$ \\
\hline & - with massive bleeding: $100 \%$ \\
\hline Interventions & Tranexamic acid $1 \mathrm{~g}$ IV 6 times/d then $1.5 \mathrm{~g}$ orally 4 times/d vs placebo \\
\hline Outcomes & Mortality, bleeding, surgery and adverse events \\
\hline Endoscopy & Performed (time frame not specified) \\
\hline Definition of re-bleeding & Not defined \\
\hline Duration of therapy & 7 days \\
\hline Notes & Funding not reported \\
\hline
\end{tabular}

\section{Risk of bias}

\begin{tabular}{|c|c|c|}
\hline Bias & Authors' judgement & Support for judgement \\
\hline $\begin{array}{l}\text { Random sequence genera- } \\
\text { tion (selection bias) }\end{array}$ & Unclear risk & Not described \\
\hline $\begin{array}{l}\text { Allocation concealment } \\
\text { (selection bias) }\end{array}$ & Low risk & Blinded administration of tranexamic acid or placebo \\
\hline $\begin{array}{l}\text { Blinding (performance } \\
\text { bias and detection bias) } \\
\text { All outcomes }\end{array}$ & Low risk & Double blinding (using placebo) \\
\hline $\begin{array}{l}\text { Blinding of participants } \\
\text { and personnel (perfor- } \\
\text { mance bias) } \\
\text { All outcomes }\end{array}$ & Low risk & Participants and personnel blinded (using placebo) \\
\hline $\begin{array}{l}\text { Blinding of outcome as- } \\
\text { sessment (detection bias) } \\
\text { All outcomes }\end{array}$ & Low risk & Outcomes assessed in a blinded manner (using placebo) \\
\hline $\begin{array}{l}\text { Incomplete outcome data } \\
\text { (attrition bias) } \\
\text { All outcomes }\end{array}$ & High risk & $\begin{array}{l}\text { Outcome measures are not reported for participants who were withdrawn or } \\
\text { excluded }(27 \%)\end{array}$ \\
\hline $\begin{array}{l}\text { Selective reporting (re- } \\
\text { porting bias) }\end{array}$ & Low risk & Mortality and bleeding are reported \\
\hline
\end{tabular}


Engquist 1979 (Continued)
Other bias
Low risk
No other apparent biases are reported

Hawkey 2001

\begin{tabular}{|c|c|}
\hline Methods & $\begin{array}{l}\text { Randomised trial comparing tranexamic acid alone vs lansoprazole vs tranexamic acid and lansopra- } \\
\text { zole vs placebo }\end{array}$ \\
\hline \multirow[t]{7}{*}{ Participants } & Inclusion criteria: patients admitted with suspected upper gastrointestinal bleeding \\
\hline & Number of participants randomly assigned: 206 \\
\hline & $\begin{array}{l}\text { Mean age tranexamic acid/control groups: } 58 / 58 \text { years } \\
\text { Proportion: }\end{array}$ \\
\hline & - of men: $61 \%$ \\
\hline & - with peptic ulcer: $37 \%$ \\
\hline & - with oesophageal varices: $14 \%$ \\
\hline & - with massive bleeding: $16 \%$ \\
\hline Interventions & $\begin{array}{l}\text { Tranexamic acid } 2 \text { g orally (bolus) then } 1 \mathrm{~g} \text { orally } 4 \text { times/d vs lansoprazole } 60 \mathrm{mg} \text { orally (bolus) then } 30 \\
\mathrm{mg} \text { orally vs tranexamic acid and lansoprazole vs placebo }\end{array}$ \\
\hline Outcomes & $\begin{array}{l}\text { All-cause mortality, bleeding-related mortality and surgery. Adverse events are reported without infor- } \\
\text { mation about intervention arms }\end{array}$ \\
\hline Endoscopy & $\begin{array}{l}\text { Endoscopy was performed on the day after admission or earlier for } 359 \text { of } 414 \text { included participants. } \\
\text { The number of participants who were not evaluated with endoscopy was } 12 \text { for placebo and } 21 \text { for } \\
\text { tranexamic acid }\end{array}$ \\
\hline Definition of re-bleeding & $\begin{array}{l}\text { New haematemesis, melena or hypotension plus a drop in haemoglobin or rebleeding seen at en- } \\
\text { doscopy }\end{array}$ \\
\hline Duration of therapy & 4 days \\
\hline \multirow[t]{2}{*}{ Notes } & Funding from Lederle Laboratories \\
\hline & Additional data received \\
\hline
\end{tabular}

\section{Risk of bias}

\begin{tabular}{|c|c|c|}
\hline Bias & Authors' judgement & Support for judgement \\
\hline $\begin{array}{l}\text { Random sequence genera- } \\
\text { tion (selection bias) }\end{array}$ & Unclear risk & Not described \\
\hline $\begin{array}{l}\text { Allocation concealment } \\
\text { (selection bias) }\end{array}$ & Low risk & Blinded administration of tranexamic acid or placebo \\
\hline $\begin{array}{l}\text { Blinding (performance } \\
\text { bias and detection bias) } \\
\text { All outcomes }\end{array}$ & Unclear risk & Double blinding (using placebo) \\
\hline $\begin{array}{l}\text { Blinding of participants } \\
\text { and personnel (perfor- } \\
\text { mance bias) } \\
\text { All outcomes }\end{array}$ & Low risk & Participants and personnel blinded (using placebo) \\
\hline
\end{tabular}


Hawkey 2001 (Continued)

Blinding of outcome as- Low risk Outcomes assessed in a blinded manner (using placebo) sessment (detection bias)

All outcomes

\begin{tabular}{lll}
$\begin{array}{l}\text { Incomplete outcome data } \\
\text { (attrition bias) } \\
\text { All outcomes }\end{array}$ & Low risk & $\begin{array}{l}\text { Although several participants were withdrawn or lost to follow-up, all random- } \\
\text { ly assigned participants are accounted for }\end{array}$ \\
\hline $\begin{array}{l}\text { Selective reporting (re- } \\
\text { porting bias) }\end{array}$ & Low risk & Mortality and bleeding are reported \\
\hline Other bias & Low risk & No other apparent biases are reported \\
\hline
\end{tabular}

Holstein 1987

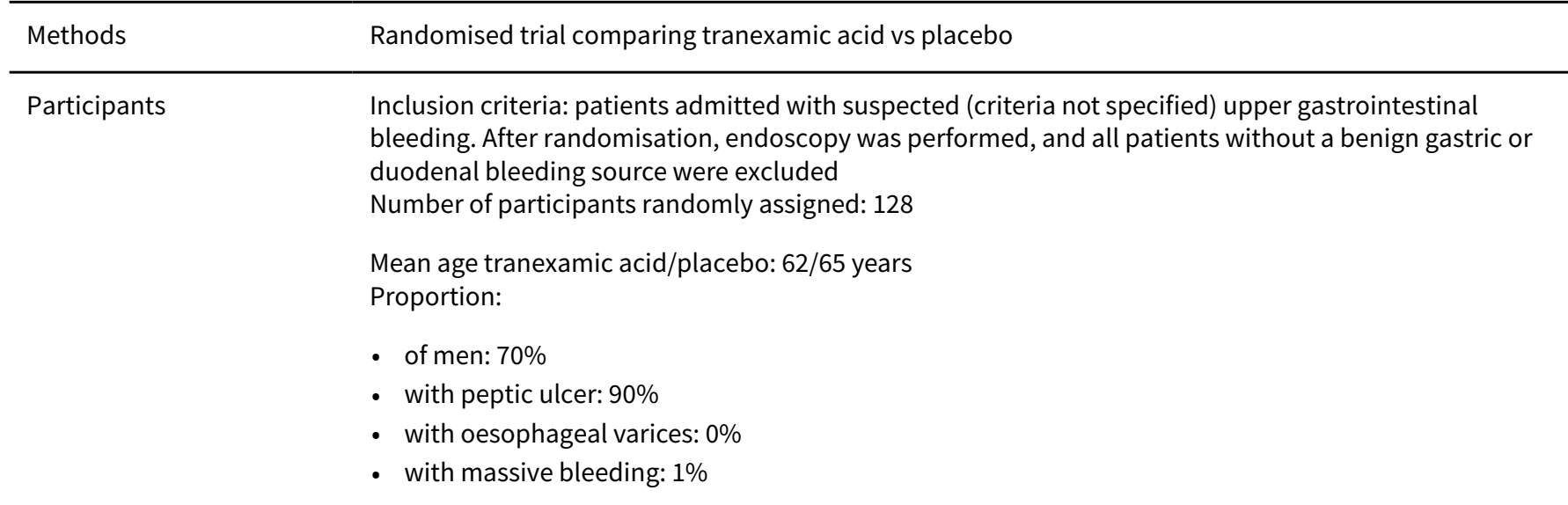

\begin{tabular}{ll}
\hline Interventions & Tranexamic acid $1 \mathrm{~g}$ IV 6 times/d then $1.5 \mathrm{~g}$ orally 4 times/d vs placebo \\
\hline Outcomes & Mortality, bleeding, surgery and adverse events \\
\hline Endoscopy & Performed within 24 hours of admission \\
\hline Definition of re-bleeding & Drop in haemoglobin of at least $20 \mathrm{~g} / \mathrm{L}$ \\
\hline Duration of therapy & 6 days \\
\hline Notes & KabiVitrum AB supplied tranexamic acid and placebo and gave advice about the trial design \\
\hline
\end{tabular}

\section{Risk of bias}

\begin{tabular}{lll}
\hline Bias & Authors' judgement & Support for judgement \\
\hline $\begin{array}{l}\text { Random sequence genera- } \\
\text { tion (selection bias) }\end{array}$ & Unclear risk & Not described \\
\hline $\begin{array}{l}\text { Allocation concealment } \\
\text { (selection bias) }\end{array}$ & Low risk & Blinded administration of tranexamic acid or placebo \\
\hline $\begin{array}{l}\text { Blinding (performance } \\
\text { bias and detection bias) }\end{array}$ & Low risk & Double blinding (using placebo) \\
All outcomes & & \\
\hline
\end{tabular}


Holstein 1987 (Continued)

Blinding of participants Low risk Participants and personnel blinded (using placebo) and personnel (performance bias)

All outcomes

\begin{tabular}{lll}
\hline $\begin{array}{l}\text { Blinding of outcome as- } \\
\text { sessment (detection bias) } \\
\text { All outcomes }\end{array}$ & Low risk & Outcomes assessed in a blinded manner (using placebo) \\
\hline $\begin{array}{l}\text { Incomplete outcome data } \\
\begin{array}{l}\text { (attrition bias) } \\
\text { All outcomes }\end{array}\end{array}$ & High risk & $\begin{array}{l}\text { Outcome measures are not reported for participants who were excluded or } \\
\text { lost to follow-up (47\%) }\end{array}$ \\
\hline $\begin{array}{l}\text { Selective reporting (re- } \\
\text { porting bias) }\end{array}$ & Low risk & Mortality and bleeding are reported \\
\hline \begin{tabular}{l} 
Other bias \\
\hline
\end{tabular} & Low risk & No other apparent biases are reported \\
\hline
\end{tabular}

IV: intravenous.

Characteristics of excluded studies [ordered by study ID]

\begin{tabular}{ll}
\hline Study & Reason for exclusion \\
\hline Adachi 2001 & Randomised trial on lansoprazole alone or with cetraxate for healing of peptic ulcers. \\
\hline Hollanders 1982 & Randomised trial on tranexamic acid for ulcerative colitis \\
\hline Sabovic 2003 & $\begin{array}{l}\text { Non-randomised trial on tranexamic acid as adjunctive therapy for upper gastrointestinal bleeding } \\
\text { in patients with renal failure }\end{array}$ \\
\hline Tam 1989 & Randomised trial on cetraxate vs ranitidine for treatment of patients with gastric ulcer
\end{tabular}

Characteristics of ongoing studies [ordered by study ID]

\section{ISRCTN11225767}

Trial name or title

Tranexamic acid for the treatment of gastrointestinal haemorrhage: an international randomised, double-blind placebo-controlled trial (Haemorrhage ALleviation with Tranexamic acid? IntesTinal system HALT-IT)

\section{Interventions \\ Tranexamic acid (loading dose $1 \mathrm{~g}$ over 10 minutes then infusion of $3 \mathrm{~g}$ over 24 hours) or matching placebo}

- Inclusion criteria: all adult patients with acute significant upper or lower gastrointestinal bleeding when the responsible clinician is substantially uncertain as to the appropriateness of antifibrinolytic agents in the patient

- Exclusion criteria: fundamental eligibility criterion: the responsible clinician's 'uncertainty' as to whether an antifibrinolytic agent should be used in a particular patient with upper or lower gastrointestinal bleeding 
ISRCTN11225767 (Continued)

\begin{tabular}{ll} 
Starting date & Date of first enrolment: January 22013 \\
\hline Contact information & Professor lan Roberts, haltit@lshtm.ac.uk \\
& Ms Haleema Shakur, haltit@lshtm.ac.uk \\
\hline Target sample size & 8000 participants \\
\hline Sponsor & London School of Hygiene and Tropical Medicine (UK) \\
\hline Conditions assessed & Upper and lower gastrointestinal bleeding \\
\hline Notes & $\begin{array}{l}\text { Funded by Health Technology Assessment programme, which is part of the National Institute for } \\
\text { Health Research (NIHR), UK }\end{array}$ \\
\hline
\end{tabular}

\section{DATA AND ANALYSES}

\section{Comparison 1. Tranexamic acid vs placebo}

\begin{tabular}{|c|c|c|c|c|}
\hline Outcome or subgroup title & $\begin{array}{l}\text { No. of } \\
\text { studies }\end{array}$ & $\begin{array}{l}\text { No. of } \\
\text { partici- } \\
\text { pants }\end{array}$ & Statistical method & Effect size \\
\hline 1 Mortality & 8 & 1701 & Risk Ratio (M-H, Random, 95\% Cl) & $0.60[0.42,0.87]$ \\
\hline $\begin{array}{l}2 \text { Mortality scenario analysis, } \\
\text { treatment failure if participant } \\
\text { missing }\end{array}$ & 8 & 1701 & Risk Ratio (M-H, Random, 95\% Cl) & $0.88[0.43,1.81]$ \\
\hline $\begin{array}{l}3 \text { Mortality in trials with low } \\
\text { risk of bias }\end{array}$ & 8 & & Risk Ratio (M-H, Random, 95\% Cl) & Subtotals only \\
\hline $\begin{array}{l}3.1 \text { Allocation sequence gener- } \\
\text { ation }\end{array}$ & 1 & 516 & Risk Ratio (M-H, Random, 95\% Cl) & $0.46[0.26,0.82]$ \\
\hline 3.2 Allocation concealment & 7 & 1654 & Risk Ratio (M-H, Random, 95\% Cl) & $0.61[0.42,0.89]$ \\
\hline 3.3 Blinding & 7 & 1654 & Risk Ratio (M-H, Random, 95\% Cl) & $0.61[0.42,0.89]$ \\
\hline 3.4 Incomplete outcome data & 1 & 206 & Risk Ratio (M-H, Random, 95\% Cl) & $0.8[0.22,2.89]$ \\
\hline 3.5 Selective reporting & 7 & 1651 & Risk Ratio (M-H, Random, 95\% Cl) & $0.60[0.41,0.89]$ \\
\hline $\begin{array}{l}4 \text { Mortality in relation to endo- } \\
\text { scopic therapy }\end{array}$ & 8 & 1701 & Risk Ratio (M-H, Random, 95\% Cl) & $0.60[0.42,0.87]$ \\
\hline $\begin{array}{l}\text { 4.1 Endoscopic therapy not } \\
\text { used }\end{array}$ & 6 & 1448 & Risk Ratio (M-H, Random, 95\% Cl) & $0.60[0.40,0.88]$ \\
\hline $\begin{array}{l}4.2 \text { Endoscopic therapy used } \\
\text { to control bleeding }\end{array}$ & 2 & 253 & Risk Ratio (M-H, Random, 95\% Cl) & $0.66[0.22,2.00]$ \\
\hline
\end{tabular}




\begin{tabular}{|c|c|c|c|c|}
\hline Outcome or subgroup title & $\begin{array}{l}\text { No. of } \\
\text { studies }\end{array}$ & $\begin{array}{l}\text { No. of } \\
\text { partici- } \\
\text { pants }\end{array}$ & Statistical method & Effect size \\
\hline $\begin{array}{l}5 \text { Mortality in relation to lan- } \\
\text { guage of publication }\end{array}$ & 8 & 1701 & Risk Ratio (M-H, Random, 95\% Cl) & $0.60[0.42,0.87]$ \\
\hline 5.1 Trials published in English & 7 & 1654 & Risk Ratio (M-H, Random, 95\% Cl) & $0.61[0.42,0.89]$ \\
\hline $\begin{array}{l}5.2 \text { Trials translated from } \\
\text { Russian }\end{array}$ & 1 & 47 & Risk Ratio (M-H, Random, 95\% Cl) & $0.38[0.04,3.38]$ \\
\hline 6 Rebleeding & 7 & 1651 & Risk Ratio (M-H, Random, 95\% Cl) & $0.72[0.50,1.03]$ \\
\hline $\begin{array}{l}7 \text { Rebleeding scenario analy- } \\
\text { sis, treatment failure if partici- } \\
\text { pant missing }\end{array}$ & 7 & 1651 & Risk Ratio (M-H, Random, 95\% Cl) & $0.80[0.51,1.27]$ \\
\hline $\begin{array}{l}8 \text { Rebleeding in trials with low } \\
\text { risk of bias }\end{array}$ & 7 & 5581 & Risk Ratio (M-H, Random, 95\% Cl) & $0.78[0.65,0.93]$ \\
\hline $\begin{array}{l}8.1 \text { Allocation sequence gener- } \\
\text { ation }\end{array}$ & 1 & 516 & Risk Ratio (M-H, Random, 95\% Cl) & $1.16[0.83,1.61]$ \\
\hline 8.2 Allocation concealment & 6 & 1604 & Risk Ratio (M-H, Random, 95\% Cl) & $0.73[0.50,1.07]$ \\
\hline 8.3 Blinding & 6 & 1604 & Risk Ratio (M-H, Random, 95\% Cl) & $0.73[0.50,1.07]$ \\
\hline 8.4 Incomplete outcome data & 1 & 206 & Risk Ratio (M-H, Random, 95\% Cl) & $0.9[0.38,2.12]$ \\
\hline 8.5 Selective reporting & 7 & 1651 & Risk Ratio (M-H, Random, 95\% Cl) & $0.72[0.50,1.03]$ \\
\hline $\begin{array}{l}9 \text { Rebleeding in relation to en- } \\
\text { doscopic therapy }\end{array}$ & 7 & 1651 & Risk Ratio (M-H, Random, 95\% Cl) & $0.72[0.50,1.03]$ \\
\hline $\begin{array}{l}\text { 9.1 Endoscopic therapy not } \\
\text { used }\end{array}$ & 5 & 1398 & Risk Ratio (M-H, Random, 95\% Cl) & $0.70[0.45,1.08]$ \\
\hline $\begin{array}{l}9.2 \text { Endoscopic therapy used } \\
\text { to control bleeding }\end{array}$ & 2 & 253 & Risk Ratio (M-H, Random, 95\% Cl) & $0.77[0.36,1.62]$ \\
\hline $\begin{array}{l}10 \text { Rebleeding in relation to } \\
\text { language of publication }\end{array}$ & 7 & 1651 & Risk Ratio (M-H, Random, 95\% Cl) & $0.72[0.50,1.03]$ \\
\hline 10.1 Trials published in English & 6 & 1604 & Risk Ratio (M-H, Random, 95\% Cl) & $0.73[0.50,1.07]$ \\
\hline $\begin{array}{l}\text { 10.2 Trials translated from } \\
\text { Russian }\end{array}$ & 1 & 47 & Risk Ratio (M-H, Random, 95\% Cl) & $0.45[0.10,2.11]$ \\
\hline $\begin{array}{l}11 \text { Myocardial infarction, pul- } \\
\text { monary embolism and cere- } \\
\text { bral infarction }\end{array}$ & 3 & 1048 & Risk Ratio (M-H, Random, 95\% Cl) & $1.37[0.36,5.28]$ \\
\hline 12 Deep venous thrombosis & 3 & 1048 & Risk Ratio (M-H, Random, 95\% Cl) & $2.32[0.60,8.89]$ \\
\hline 13 Any thromboembolic event & 4 & 1095 & Risk Ratio (M-H, Random, 95\% Cl) & $1.86[0.66,5.24]$ \\
\hline 14 Surgery & 7 & 1551 & Risk Ratio (M-H, Random, 95\% Cl) & $0.61[0.35,1.04]$ \\
\hline
\end{tabular}




\begin{tabular}{lllll}
\hline Outcome or subgroup title & $\begin{array}{l}\text { No. of } \\
\text { studies }\end{array}$ & $\begin{array}{l}\text { No. of } \\
\text { partici- } \\
\text { pants }\end{array}$ & Statistical method & Effect size \\
\hline 15 Transfusion required & 5 & 931 & Risk Ratio (M-H, Random, 95\% Cl) & $1.02[0.94,1.11]$ \\
\hline
\end{tabular}

Analysis 1.1. Comparison 1 Tranexamic acid vs placebo, Outcome 1 Mortality.

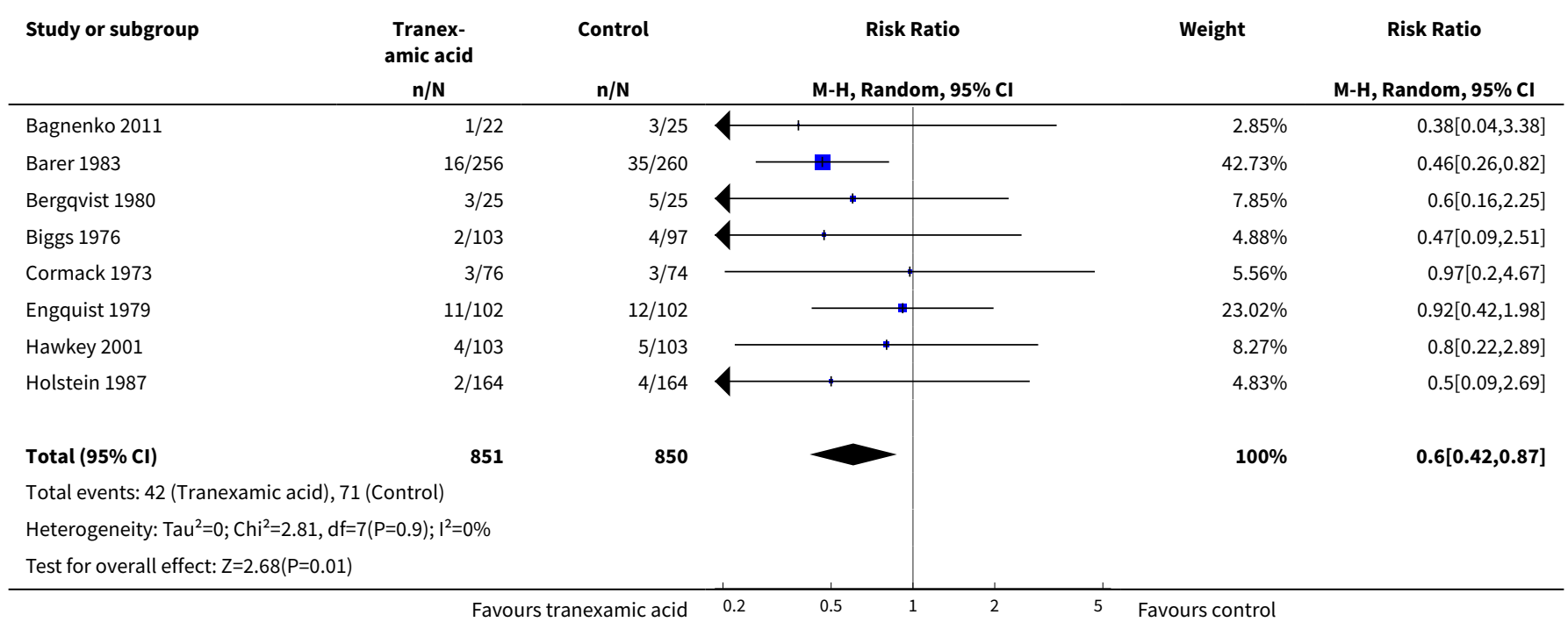

Analysis 1.2. Comparison 1 Tranexamic acid vs placebo, Outcome 2 Mortality scenario analysis, treatment failure if participant missing.

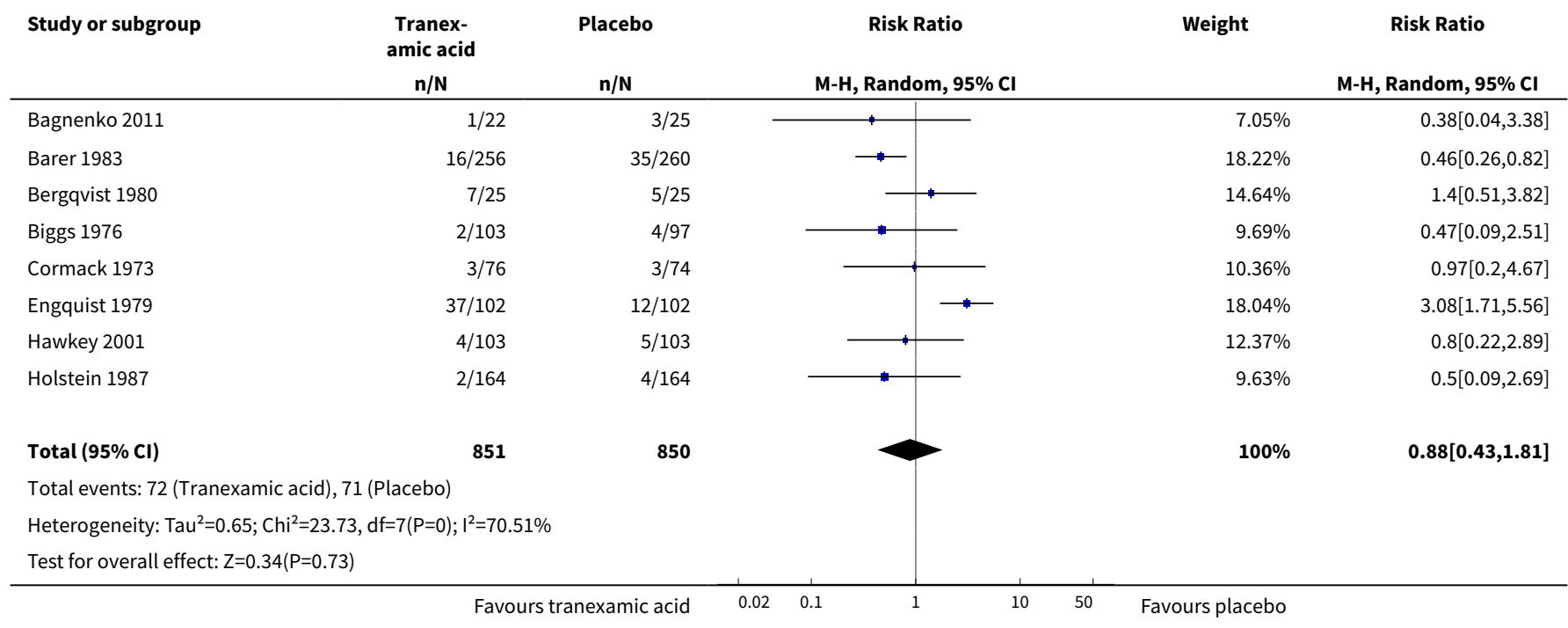


Analysis 1.3. Comparison 1 Tranexamic acid vs placebo, Outcome 3 Mortality in trials with low risk of bias.

\begin{tabular}{|c|c|c|c|c|c|}
\hline Study or subgroup & $\begin{array}{c}\text { Tranex- } \\
\text { amic acid } \\
\mathbf{n} / \mathbf{N}\end{array}$ & $\begin{array}{l}\text { Placebo } \\
\text { n/N }\end{array}$ & $\begin{array}{c}\text { Risk Ratio } \\
\text { M-H, Random, } 95 \% \mathrm{CI}\end{array}$ & Weight & $\begin{array}{c}\text { Risk Ratio } \\
\text { M-H, Random, } 95 \% \mathrm{CI}\end{array}$ \\
\hline \multicolumn{6}{|c|}{ 1.3.1 Allocation sequence generation } \\
\hline Barer 1983 & $16 / 256$ & $35 / 260$ & & $100 \%$ & $0.46[0.26,0.82]$ \\
\hline Subtotal $(95 \% \mathrm{Cl})$ & 256 & 260 & & $100 \%$ & $0.46[0.26,0.82]$ \\
\hline \multicolumn{6}{|c|}{ Total events: 16 (Tranexamic acid), 35 (Placebo) } \\
\hline \multicolumn{6}{|c|}{ Heterogeneity: Not applicable } \\
\hline \multicolumn{6}{|c|}{ Test for overall effect: $Z=2.66(P=0.01)$} \\
\hline \multicolumn{6}{|c|}{ 1.3.2 Allocation concealment } \\
\hline Barer 1983 & $16 / 256$ & $35 / 260$ & & $43.99 \%$ & $0.46[0.26,0.82]$ \\
\hline Bergqvist 1980 & $3 / 25$ & $5 / 25$ & & $8.08 \%$ & $0.6[0.16,2.25]$ \\
\hline Biggs 1976 & $2 / 103$ & $4 / 97$ & & $5.02 \%$ & $0.47[0.09,2.51]$ \\
\hline Engquist 1979 & $11 / 102$ & $12 / 102$ & - & $23.7 \%$ & $0.92[0.42,1.98]$ \\
\hline Hawkey 2001 & $4 / 103$ & $5 / 103$ & 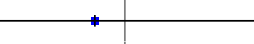 & $8.51 \%$ & $0.8[0.22,2.89]$ \\
\hline Holstein 1987 & $2 / 164$ & $4 / 164$ & & $4.97 \%$ & $0.5[0.09,2.69]$ \\
\hline Subtotal $(95 \% \mathrm{Cl})$ & 829 & 825 & & $100 \%$ & $0.61[0.42,0.89]$ \\
\hline \multicolumn{6}{|c|}{ Total events: 41 (Tranexamic acid), 68 (Placebo) } \\
\hline \multicolumn{6}{|c|}{ Heterogeneity: $\operatorname{Tau}^{2}=0 ; \mathrm{Chi}^{2}=2.63, \mathrm{df}=6(\mathrm{P}=0.85) ; \mathrm{I}^{2}=0 \%$} \\
\hline \multicolumn{6}{|c|}{ Test for overall effect: $Z=2.57(P=0.01)$} \\
\hline \multicolumn{6}{|l|}{ 1.3.3 Blinding } \\
\hline Barer 1983 & $16 / 256$ & $35 / 260$ & & $43.99 \%$ & $0.46[0.26,0.82]$ \\
\hline Bergqvist 1980 & $3 / 25$ & $5 / 25$ & & $8.08 \%$ & $0.6[0.16,2.25]$ \\
\hline Biggs 1976 & $2 / 103$ & $4 / 97$ & & $5.02 \%$ & $0.47[0.09,2.51]$ \\
\hline Cormack 1973 & $3 / 76$ & $3 / 74$ & & $5.73 \%$ & $0.97[0.2,4.67]$ \\
\hline Holstein 1987 & $2 / 164$ & $4 / 164$ & & $4.97 \%$ & $0.5[0.09,2.69]$ \\
\hline Subtotal $(95 \% \mathrm{Cl})$ & 829 & 825 & & $100 \%$ & $0.61[0.42,0.89]$ \\
\hline \multicolumn{6}{|c|}{ Total events: 41 (Tranexamic acid), 68 (Placebo) } \\
\hline \multicolumn{6}{|c|}{ Heterogeneity: $\operatorname{Tau}^{2}=0 ; \mathrm{Chi}^{2}=2.63, \mathrm{df}=6(\mathrm{P}=0.85) ; \mathrm{I}^{2}=0 \%$} \\
\hline \multicolumn{6}{|c|}{ Test for overall effect: $Z=2.57(P=0.01)$} \\
\hline \multicolumn{6}{|c|}{ 1.3.4 Incomplete outcome data } \\
\hline Hawkey 2001 & $4 / 103$ & $5 / 103$ & & $100 \%$ & $0.8[0.22,2.89]$ \\
\hline Subtotal $(95 \% \mathrm{Cl})$ & 103 & 103 & & $100 \%$ & $0.8[0.22,2.89]$ \\
\hline \multicolumn{6}{|c|}{ Total events: 4 (Tranexamic acid), 5 (Placebo) } \\
\hline \multicolumn{6}{|c|}{ Heterogeneity: Not applicable } \\
\hline \multicolumn{6}{|c|}{ Test for overall effect: $Z=0.34(P=0.73)$} \\
\hline \multicolumn{6}{|c|}{ 1.3.5 Selective reporting } \\
\hline Bagnenko 2011 & $1 / 22$ & $3 / 25$ & & $3.1 \%$ & $0.38[0.04,3.38]$ \\
\hline Barer 1983 & $16 / 256$ & $35 / 260$ & & $46.37 \%$ & $0.46[0.26,0.82]$ \\
\hline Biggs 1976 & $2 / 103$ & $4 / 97$ & & $5.29 \%$ & $0.47[0.09,2.51]$ \\
\hline Cormack 1973 & $3 / 76$ & $3 / 74$ & & $6.04 \%$ & $0.97[0.2,4.67]$ \\
\hline Engquist 1979 & $11 / 102$ & $12 / 102$ & $\rightarrow$ & $24.99 \%$ & $0.92[0.42,1.98]$ \\
\hline Hawkey 2001 & $4 / 103$ & $5 / 103$ & & $8.97 \%$ & $0.8[0.22,2.89]$ \\
\hline Holstein 1987 & $2 / 164$ & $4 / 164$ & & $5.24 \%$ & $0.5[0.09,2.69]$ \\
\hline Subtotal $(95 \% \mathrm{Cl})$ & 826 & 825 & & $100 \%$ & $0.6[0.41,0.89]$ \\
\hline
\end{tabular}




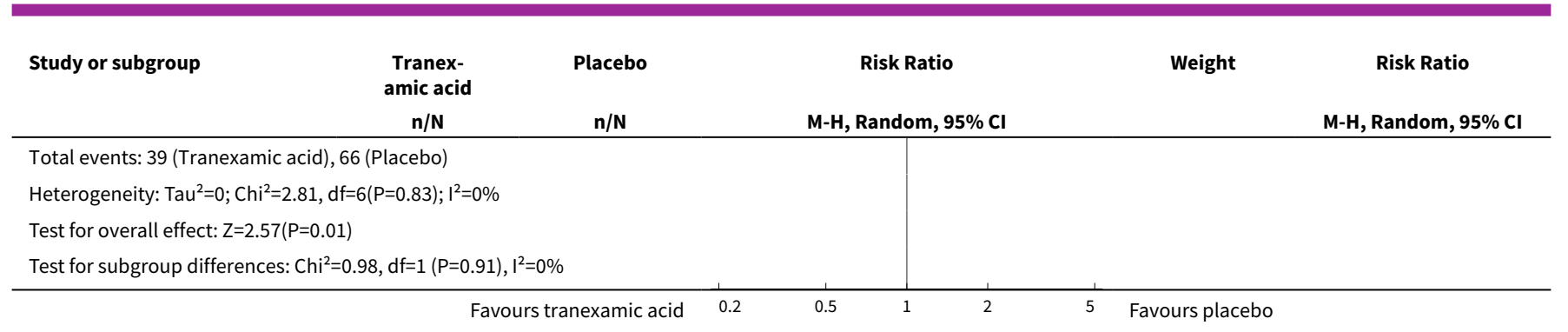

\section{Analysis 1.4. Comparison 1 Tranexamic acid vs placebo, Outcome 4 Mortality in relation to endoscopic therapy.}

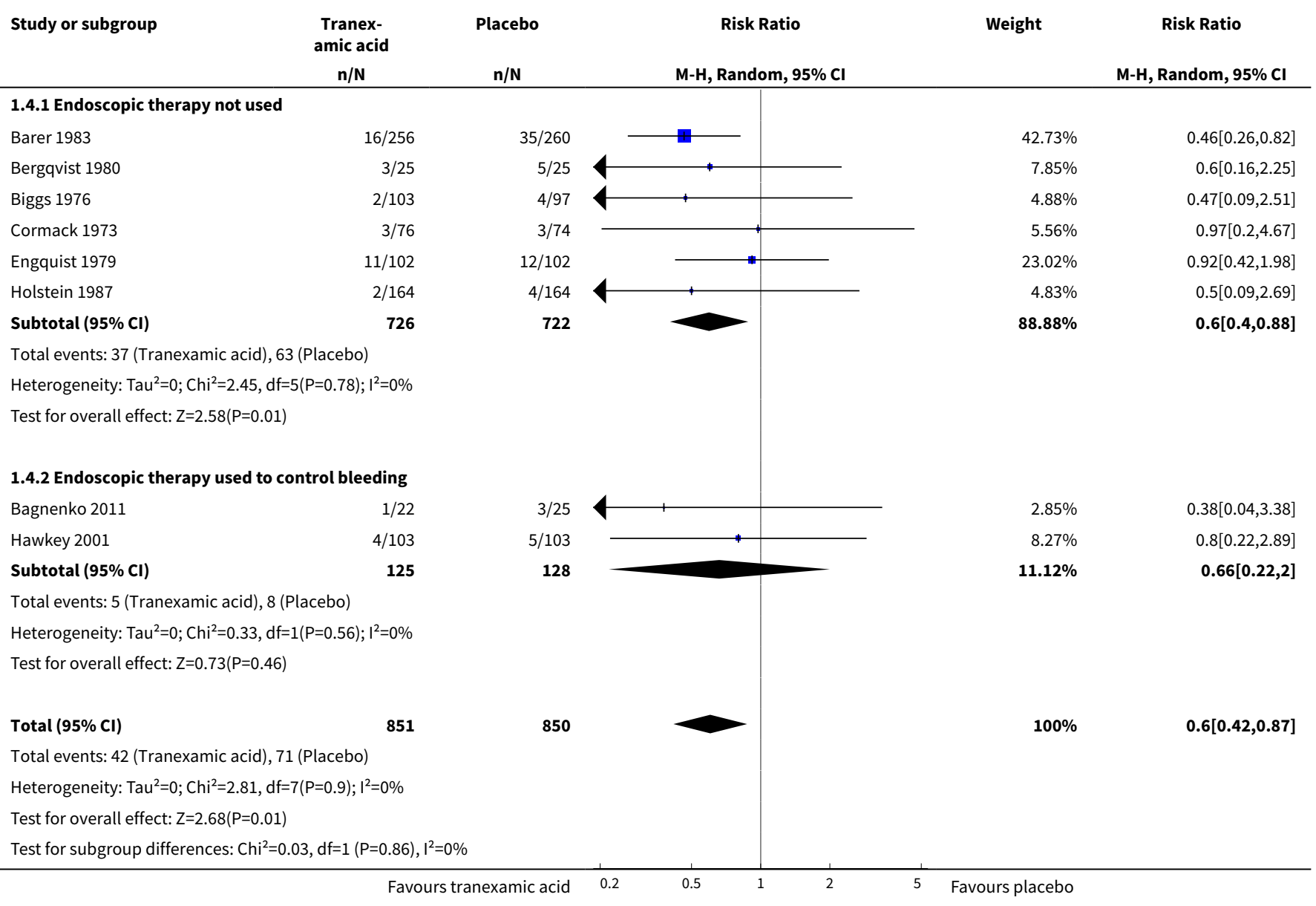

Analysis 1.5. Comparison 1 Tranexamic acid vs placebo, Outcome 5 Mortality in relation to language of publication.

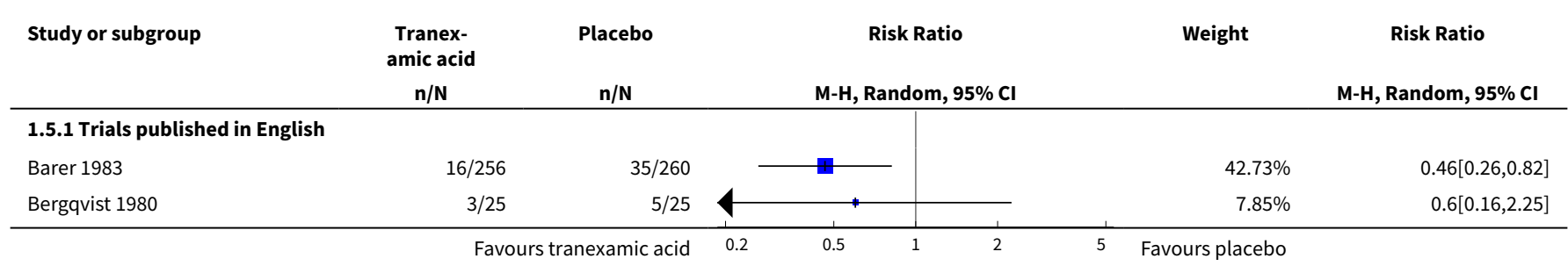




\begin{tabular}{|c|c|c|c|c|c|}
\hline Study or subgroup & $\begin{array}{l}\text { Tranex- } \\
\text { amic acid } \\
n / N\end{array}$ & $\begin{array}{l}\text { Placebo } \\
\text { n/N }\end{array}$ & $\begin{array}{c}\text { Risk Ratio } \\
\text { M-H, Random, } 95 \% \mathrm{CI}\end{array}$ & Weight & $\begin{array}{c}\text { Risk Ratio } \\
\text { M-H, Random, } 95 \% \mathrm{Cl}\end{array}$ \\
\hline Biggs 1976 & $2 / 103$ & $4 / 97$ & & $4.88 \%$ & $0.47[0.09,2.51]$ \\
\hline Cormack 1973 & $3 / 76$ & $3 / 74$ & & $5.56 \%$ & $0.97[0.2,4.67]$ \\
\hline Engquist 1979 & $11 / 102$ & $12 / 102$ & $\longrightarrow$ & $23.02 \%$ & $0.92[0.42,1.98]$ \\
\hline Holstein 1987 & $2 / 164$ & $4 / 164$ & & $4.83 \%$ & $0.5[0.09,2.69]$ \\
\hline Subtotal $(95 \% \mathrm{Cl})$ & 829 & 825 & & $97.15 \%$ & $0.61[0.42,0.89]$ \\
\hline \multicolumn{6}{|c|}{ Total events: 41 (Tranexamic acid), 68 (Placebo) } \\
\hline \multicolumn{6}{|c|}{ Heterogeneity: $\operatorname{Tau}^{2}=0 ; \mathrm{Chi}^{2}=2.63, \mathrm{df}=6(\mathrm{P}=0.85) ; \mathrm{I}^{2}=0 \%$} \\
\hline \multicolumn{6}{|c|}{ Test for overall effect: $Z=2.57(P=0.01)$} \\
\hline \multicolumn{6}{|c|}{ 1.5.2 Trials translated from Russian } \\
\hline Bagnenko 2011 & $1 / 22$ & $3 / 25$ & & $2.85 \%$ & $0.38[0.04,3.38]$ \\
\hline Subtotal $(95 \% \mathrm{Cl})$ & 22 & 25 & & $2.85 \%$ & $0.38[0.04,3.38]$ \\
\hline \multicolumn{6}{|c|}{ Total events: 1 (Tranexamic acid), 3 (Placebo) } \\
\hline \multicolumn{6}{|c|}{ Heterogeneity: Not applicable } \\
\hline \multicolumn{6}{|c|}{ Test for overall effect: $Z=0.87(P=0.38)$} \\
\hline Total $(95 \% \mathrm{Cl})$ & 851 & 850 & & $100 \%$ & $0.6[0.42,0.87]$ \\
\hline \multicolumn{6}{|c|}{ Total events: 42 (Tranexamic acid), 71 (Placebo) } \\
\hline \multicolumn{6}{|c|}{ Heterogeneity: $\mathrm{Tau}^{2}=0 ; \mathrm{Chi}^{2}=2.81, \mathrm{df}=7(\mathrm{P}=0.9) ; \mathrm{I}^{2}=0 \%$} \\
\hline \multicolumn{6}{|c|}{ Test for overall effect: $Z=2.68(P=0.01)$} \\
\hline Test for subgroup dif &,$d f=1(P=0.67)$ & & & & \\
\hline
\end{tabular}

Analysis 1.6. Comparison 1 Tranexamic acid vs placebo, Outcome 6 Rebleeding.

\begin{tabular}{|c|c|c|c|c|c|}
\hline Study or subgroup & $\begin{array}{c}\text { Tranex- } \\
\text { amic acid } \\
n / N\end{array}$ & Placebo & M-H, Random, 95\% Cl & Weight & M-H, Random, 95\% CI \\
\hline Bagnenko 2011 & $2 / 22$ & $5 / 25$ & & $4.67 \%$ & $0.45[0.1,2.11]$ \\
\hline Barer 1983 & $58 / 256$ & $51 / 260$ & & $25.51 \%$ & $1.16[0.83,1.61]$ \\
\hline Biggs 1976 & $7 / 103$ & $21 / 97$ & & $12.28 \%$ & $0.31[0.14,0.71]$ \\
\hline Cormack 1973 & $8 / 76$ & $11 / 74$ & & $11.49 \%$ & $0.71[0.3,1.66]$ \\
\hline Engquist 1979 & $23 / 102$ & $29 / 102$ & & $20.86 \%$ & $0.79[0.49,1.27]$ \\
\hline Hawkey 2001 & $9 / 103$ & $10 / 103$ & & $11.39 \%$ & $0.9[0.38,2.12]$ \\
\hline Holstein 1987 & $10 / 164$ & $19 / 164$ & & $13.8 \%$ & $0.53[0.25,1.1]$ \\
\hline Total $(95 \% \mathrm{Cl})$ & 826 & 825 & & $100 \%$ & $0.72[0.5,1.03]$ \\
\hline \multicolumn{6}{|c|}{ Total events: 117 (Tranexamic acid), 146 (Placebo) } \\
\hline \multicolumn{6}{|c|}{ Heterogeneity: $\mathrm{Tau}^{2}=0.1 ; \mathrm{Chi}^{2}=11.67, \mathrm{df}=6(\mathrm{P}=0.07) ; \mathrm{I}^{2}=48.59 \%$} \\
\hline
\end{tabular}


Analysis 1.7. Comparison 1 Tranexamic acid vs placebo, Outcome 7

Rebleeding scenario analysis, treatment failure if participant missing.

\begin{tabular}{|c|c|c|c|c|c|}
\hline \multirow[t]{2}{*}{ Study or subgroup } & $\begin{array}{l}\text { Tranex- } \\
\text { amic acid }\end{array}$ & Placebo & Risk Ratio & Weight & \multirow{2}{*}{$\begin{array}{c}\text { Risk Ratio } \\
\text { M-H, Random, } 95 \% \mathrm{CI}\end{array}$} \\
\hline & $n / N$ & $n / N$ & \multicolumn{2}{|l|}{ M-H, Random, $95 \% \mathrm{CI}$} & \\
\hline Bagnenko 2011 & $2 / 22$ & $5 / 25$ & & $6.41 \%$ & $0.45[0.1,2.11]$ \\
\hline Barer 1983 & $58 / 256$ & $51 / 260$ & & $20.39 \%$ & $1.16[0.83,1.61]$ \\
\hline Biggs 1976 & $7 / 103$ & $21 / 97$ & & $13.36 \%$ & $0.31[0.14,0.71]$ \\
\hline Cormack 1973 & $8 / 76$ & $11 / 74$ & & $12.78 \%$ & $0.71[0.3,1.66]$ \\
\hline Hawkey 2001 & $9 / 103$ & $10 / 103$ & & $12.7 \%$ & $0.9[0.38,2.12]$ \\
\hline Holstein 1987 & $10 / 164$ & $19 / 164$ & & $14.42 \%$ & $0.53[0.25,1.1]$ \\
\hline Total $(95 \% \mathrm{Cl})$ & 826 & 825 & & $100 \%$ & $0.8[0.51,1.27]$ \\
\hline \multicolumn{6}{|c|}{ Total events: 143 (Tranexamic acid), 146 (Placebo) } \\
\hline \multicolumn{6}{|c|}{ Heterogeneity: $\mathrm{Tau}^{2}=0.24 ; \mathrm{Chi}^{2}=21.24, \mathrm{df}=6(\mathrm{P}=0) ; \mathrm{I}^{2}=71.75 \%$} \\
\hline
\end{tabular}

Analysis 1.8. Comparison 1 Tranexamic acid vs placebo, Outcome 8 Rebleeding in trials with low risk of bias.

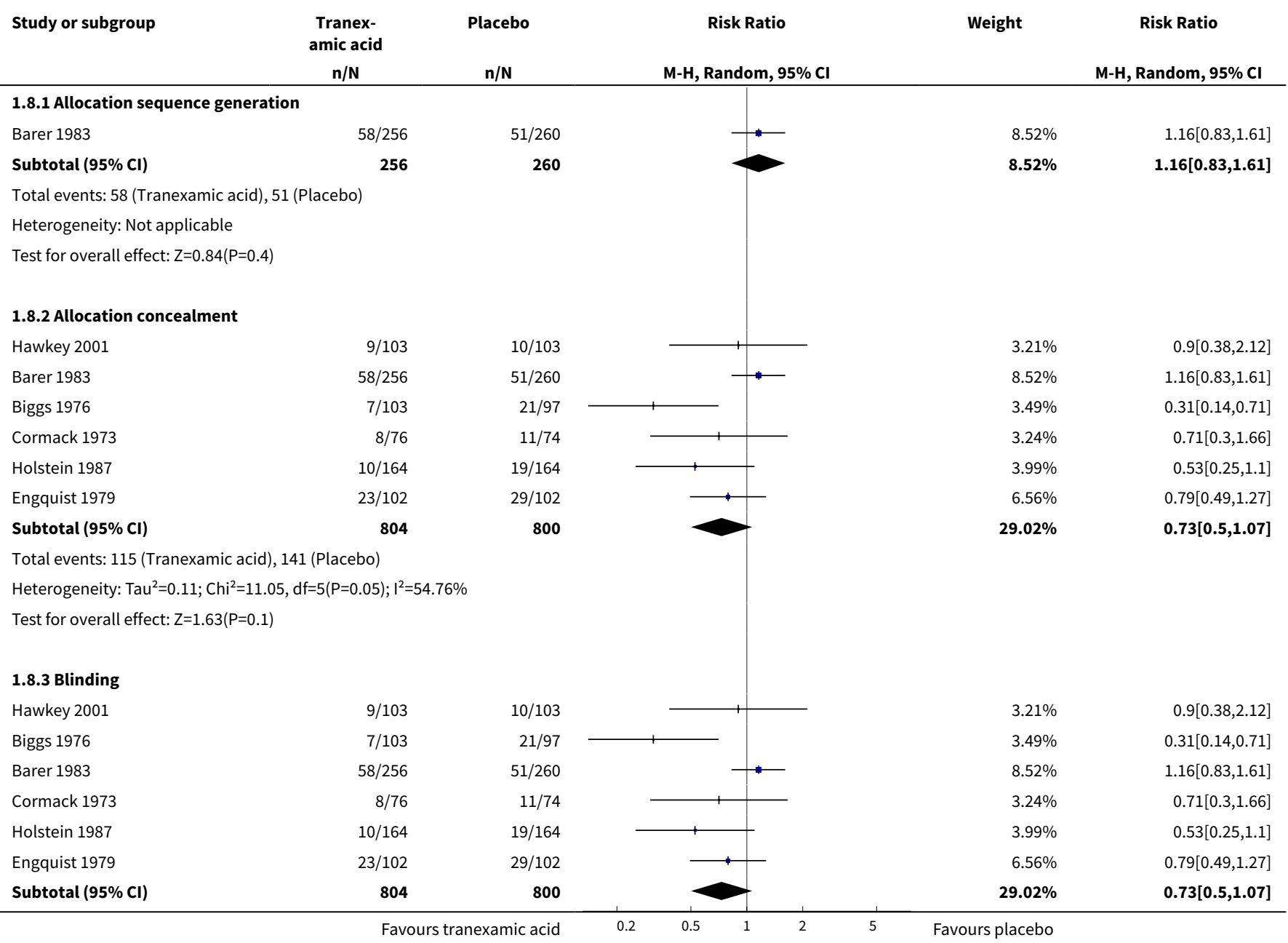




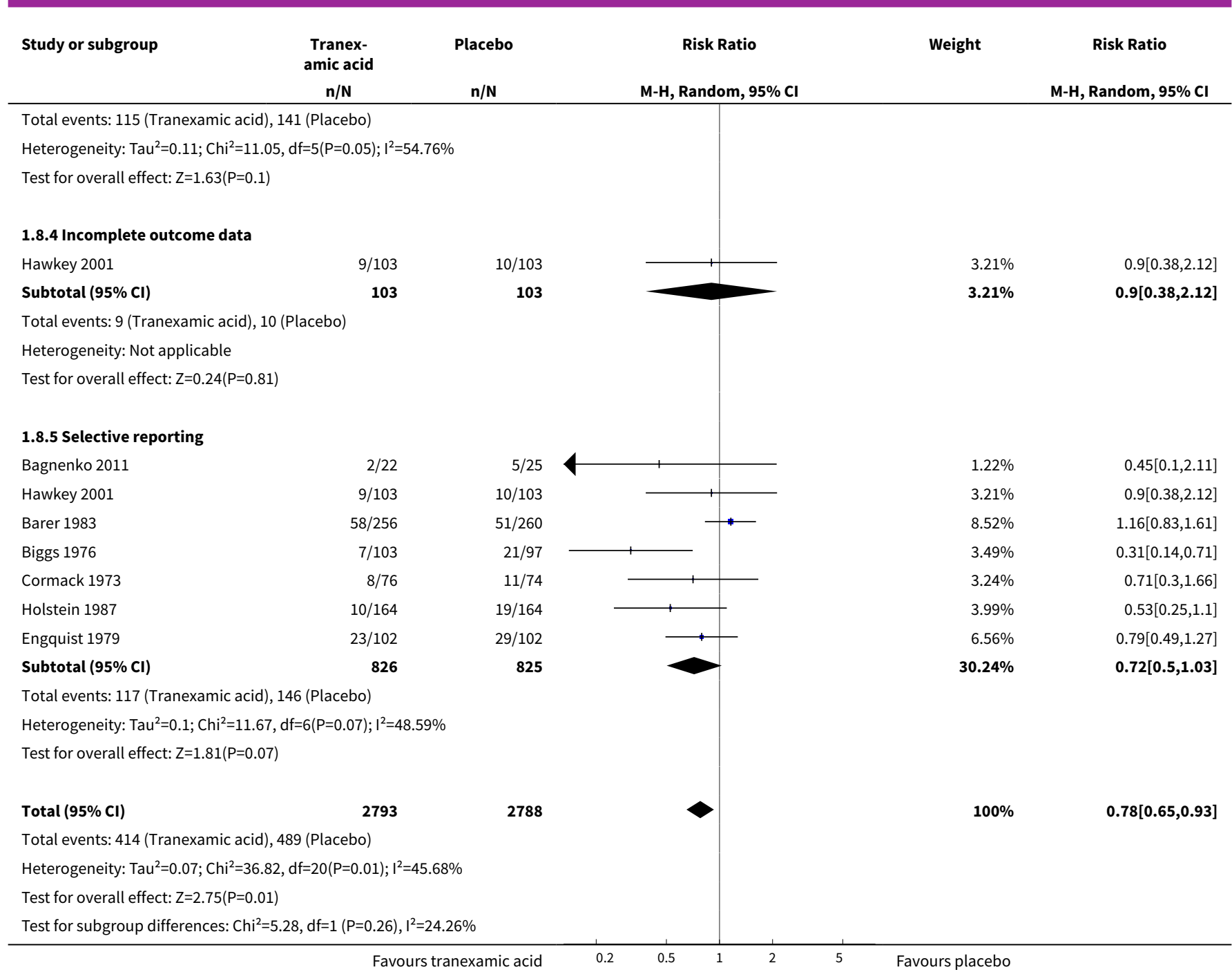

Analysis 1.9. Comparison 1 Tranexamic acid vs placebo, Outcome 9 Rebleeding in relation to endoscopic therapy.

\begin{tabular}{ccccc} 
Study or subgroup & $\begin{array}{c}\text { Tranex- } \\
\text { amic acid } \\
\mathrm{n} / \mathrm{N}\end{array}$ & $\mathrm{n} / \mathrm{N}$ & Risk Ratio & Reight \\
\hline
\end{tabular}

\begin{tabular}{|c|c|c|c|c|c|}
\hline & $n / N$ & $\mathrm{n} / \mathrm{N}$ & M-H, Random, 95\% Cl & & M-H, Random, 95\% Cl \\
\hline \multicolumn{6}{|c|}{ 1.9.1 Endoscopic therapy not used } \\
\hline Barer 1983 & $58 / 256$ & $51 / 260$ & 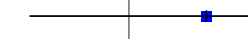 & $25.51 \%$ & $1.16[0.83,1.61]$ \\
\hline Biggs 1976 & $7 / 103$ & $21 / 97$ & & $12.28 \%$ & $0.31[0.14,0.71]$ \\
\hline Cormack 1973 & $8 / 76$ & $11 / 74$ & & $11.49 \%$ & $0.71[0.3,1.66]$ \\
\hline Engquist 1979 & $23 / 102$ & $29 / 102$ & & $20.86 \%$ & $0.79[0.49,1.27]$ \\
\hline Holstein 1987 & $10 / 164$ & $19 / 164$ & & $13.8 \%$ & $0.53[0.25,1.1]$ \\
\hline \multicolumn{6}{|c|}{ Total events: 106 (Tranexamic acid), 131 (Placebo) } \\
\hline \multicolumn{6}{|c|}{ Heterogeneity: $\mathrm{Tau}^{2}=0.15 ; \mathrm{Chi}^{2}=11.04, \mathrm{df}=4(\mathrm{P}=0.03) ; \mathrm{I}^{2}=63.77 \%$} \\
\hline \multicolumn{6}{|c|}{ Test for overall effect: $Z=1.6(P=0.11)$} \\
\hline \multicolumn{6}{|c|}{ 1.9.2 Endoscopic therapy used to control bleeding } \\
\hline Bagnenko 2011 & $2 / 22$ & $5 / 25$ & & $4.67 \%$ & $0.45[0.1,2.11]$ \\
\hline
\end{tabular}




\begin{tabular}{|c|c|c|c|c|c|}
\hline Study or subgroup & $\begin{array}{c}\text { Tranex- } \\
\text { amic acid } \\
n / N\end{array}$ & Placebo & $\begin{array}{c}\text { Risk Ratio } \\
\text { M-H, Random, 95\% CI }\end{array}$ & Weight & $\begin{array}{c}\text { Risk Ratio } \\
\text { M-H, Random, } 95 \% \mathrm{CI}\end{array}$ \\
\hline Hawkey 2001 & $9 / 103$ & $10 / 103$ & 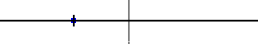 & $11.39 \%$ & $0.9[0.38,2.12]$ \\
\hline Subtotal $(95 \% \mathrm{Cl})$ & 125 & 128 & & $16.06 \%$ & $0.77[0.36,1.62]$ \\
\hline \multicolumn{6}{|c|}{ Total events: 11 (Tranexamic acid), 15 (Placebo) } \\
\hline \multicolumn{6}{|c|}{ Test for overall effect: $Z=0.7(P=0.48)$} \\
\hline Total $(95 \% \mathrm{Cl})$ & 826 & 825 & & $100 \%$ & $0.72[0.5,1.03]$ \\
\hline \multicolumn{6}{|c|}{ Total events: 117 (Tranexamic acid), 146 (Placebo) } \\
\hline \multicolumn{6}{|c|}{ Heterogeneity: Tau $^{2}=0.1 ; \mathrm{Chi}^{2}=11.67, \mathrm{df}=6(\mathrm{P}=0.07) ; \mathrm{I}^{2}=48.59 \%$} \\
\hline \multicolumn{6}{|c|}{ Test for overall effect: $\mathrm{Z}=1.81(\mathrm{P}=0.07)$} \\
\hline
\end{tabular}

\section{Analysis 1.10. Comparison 1 Tranexamic acid vs placebo, Outcome 10 Rebleeding in relation to language of publication.}

\begin{tabular}{ccccc} 
Study or subgroup & $\begin{array}{c}\text { Tranex- } \\
\text { amic acid } \\
\mathrm{n} / \mathrm{N}\end{array}$ & $\mathrm{n} / \mathrm{N}$ & Risk Ratio & Reight \\
\hline
\end{tabular}

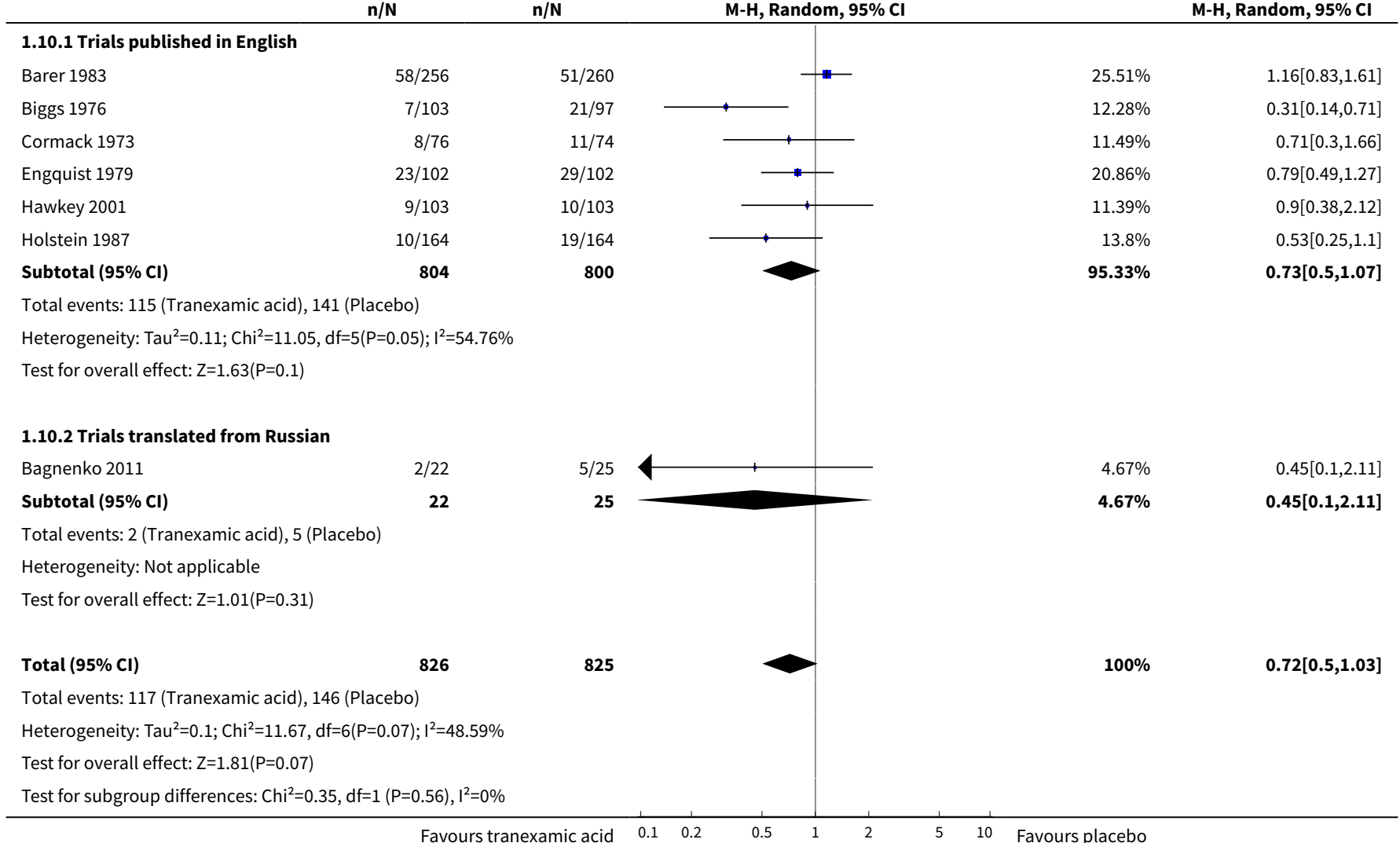


Analysis 1.11. Comparison 1 Tranexamic acid vs placebo, Outcome 11 Myocardial infarction, pulmonary embolism and cerebral infarction.

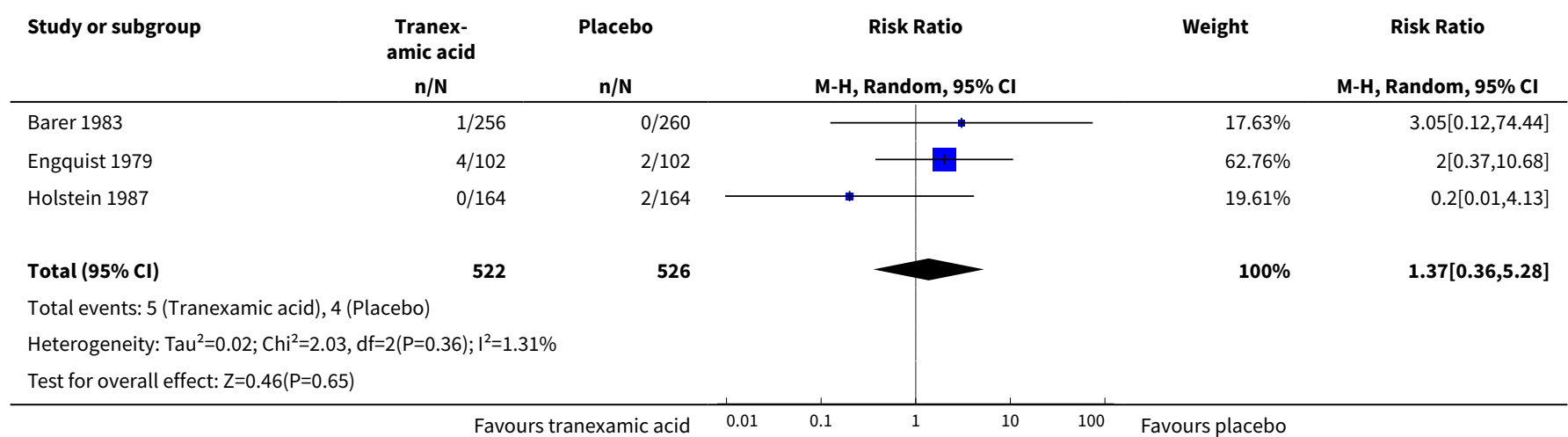

Analysis 1.12. Comparison 1 Tranexamic acid vs placebo, Outcome 12 Deep venous thrombosis.

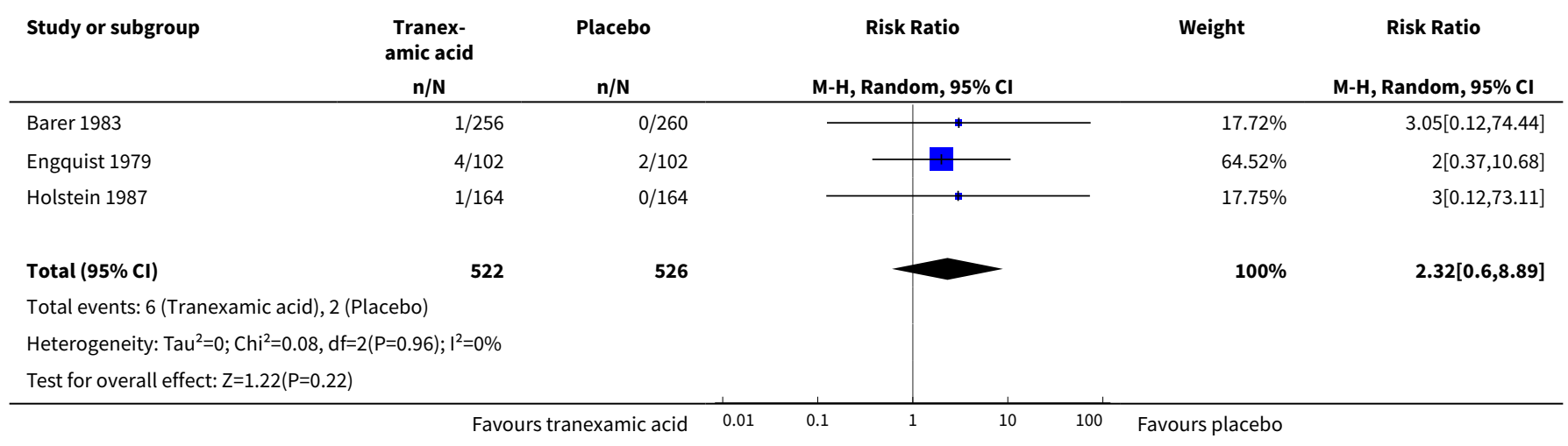

Analysis 1.13. Comparison 1 Tranexamic acid vs placebo, Outcome 13 Any thromboembolic event.

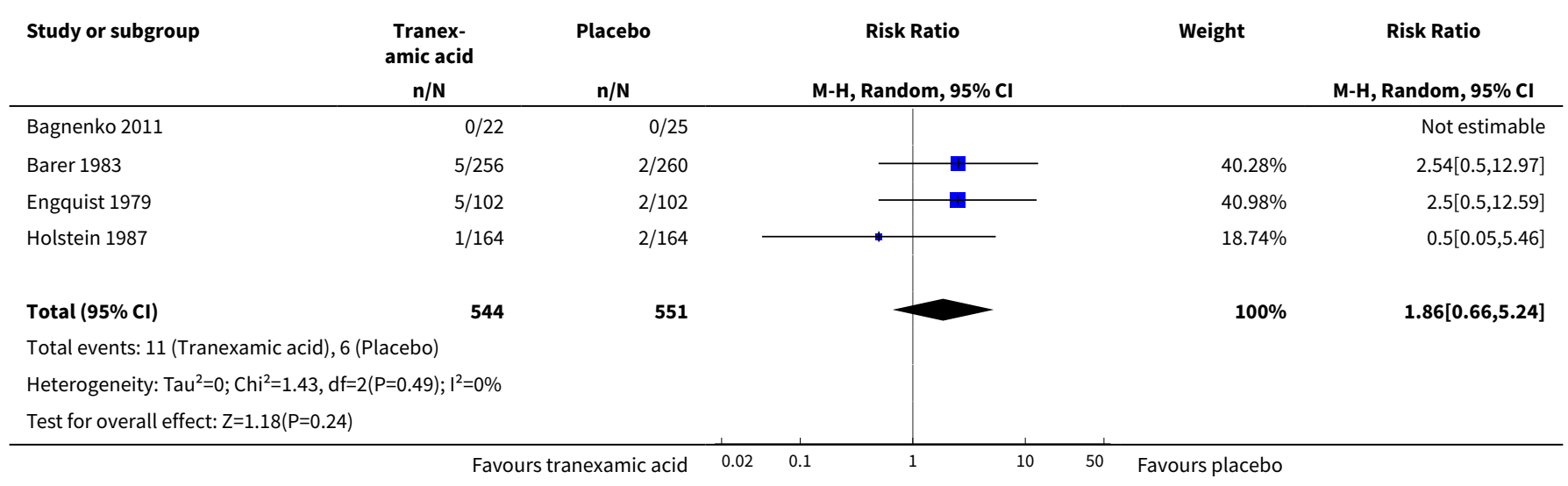


Analysis 1.14. Comparison 1 Tranexamic acid vs placebo, Outcome 14 Surgery.

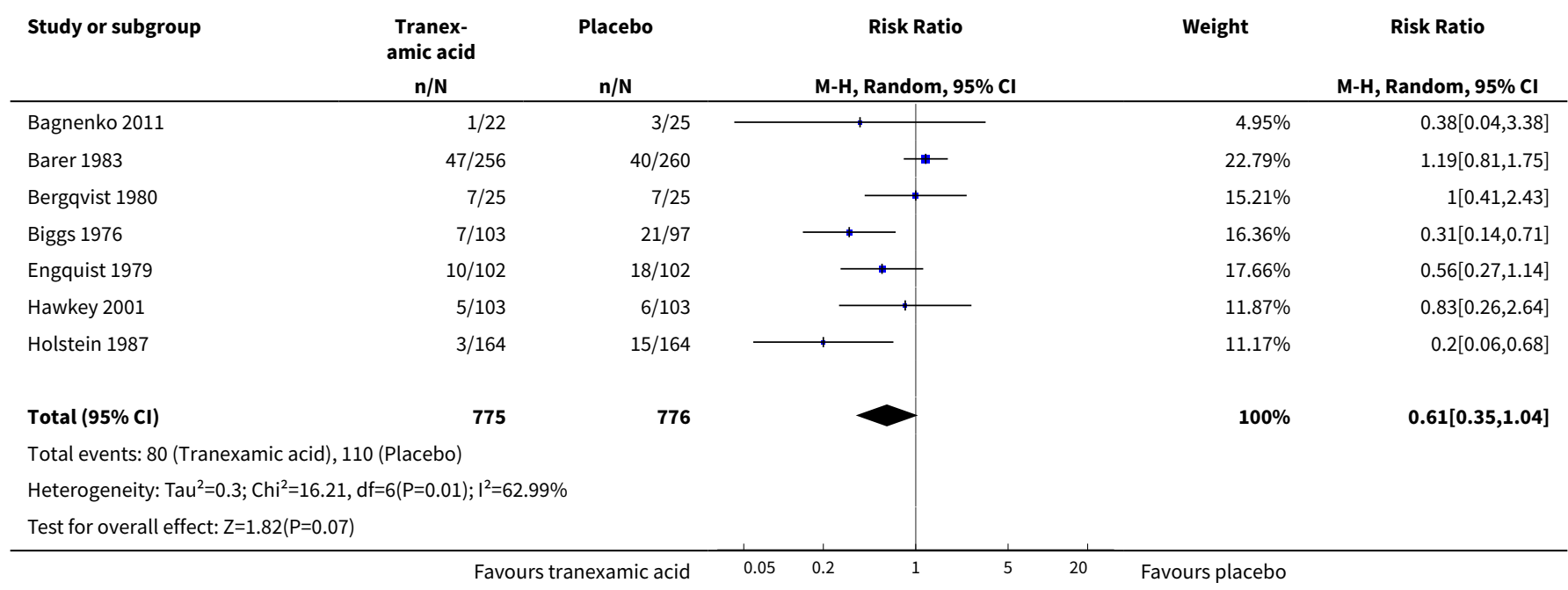

Analysis 1.15. Comparison 1 Tranexamic acid vs placebo, Outcome 15 Transfusion required.

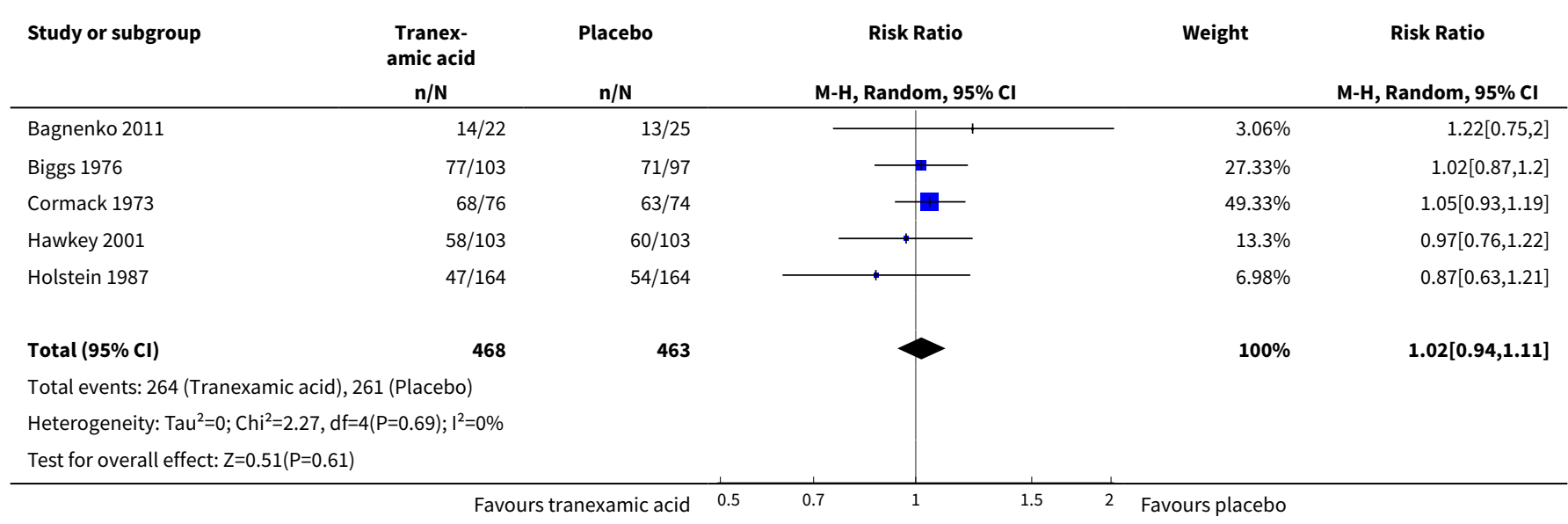

\section{Comparison 2. Tranexamic acid vs cimetidine or lansoprazole}

\begin{tabular}{lllll}
\hline $\begin{array}{l}\text { Outcome or subgroup } \\
\text { title }\end{array}$ & $\begin{array}{l}\text { No. of } \\
\text { studies }\end{array}$ & $\begin{array}{l}\text { No. of } \\
\text { partici- } \\
\text { pants }\end{array}$ & Statistical method & Effect size \\
\hline 1 Mortality & 2 & 720 & Risk Ratio (M-H, Random, 95\% Cl) & $0.91[0.50,1.64]$ \\
\hline 2 Bleeding & 2 & 720 & Risk Ratio (M-H, Random, 95\% Cl) & $0.87[0.64,1.20]$ \\
\hline 3 Surgery & 2 & 720 & Risk Ratio (M-H, Random, 95\% Cl) & $0.83[0.54,1.26]$ \\
\hline 4 Transfusion & 2 & 720 & Risk Ratio (M-H, Random, 95\% Cl) & $0.97[0.78,1.22]$ \\
\hline
\end{tabular}


Analysis 2.1. Comparison 2 Tranexamic acid vs cimetidine or lansoprazole, Outcome 1 Mortality.

\begin{tabular}{|c|c|c|c|c|c|}
\hline Study or subgroup & $\begin{array}{c}\text { Tranex- } \\
\text { amic acid } \\
n / N\end{array}$ & $\begin{array}{c}\text { Cimetidine or } \\
\text { lansoprazole } \\
\text { n/N }\end{array}$ & M-H, Random, $95 \% \mathrm{CI}$ & Weight & M-H, Random, 95\% Cl \\
\hline Barer 1983 & $16 / 256$ & $20 / 259$ & & $87.46 \%$ & $0.81[0.43,1.53]$ \\
\hline Hawkey 2001 & $4 / 103$ & $2 / 102$ & $\longrightarrow$ & $12.54 \%$ & $1.98[0.37,10.58]$ \\
\hline Total $(95 \% \mathrm{Cl})$ & 359 & 361 & & $100 \%$ & $0.91[0.5,1.64]$ \\
\hline \multicolumn{6}{|c|}{ Heterogeneity: $\mathrm{Tau}^{2}=0 ; \mathrm{Chi}^{2}=0.96, \mathrm{df}=1(\mathrm{P}=0.33) ; \mathrm{I}^{2}=0 \%$} \\
\hline Test for overall effect & & & & & \\
\hline
\end{tabular}

Analysis 2.2. Comparison 2 Tranexamic acid vs cimetidine or lansoprazole, Outcome 2 Bleeding.

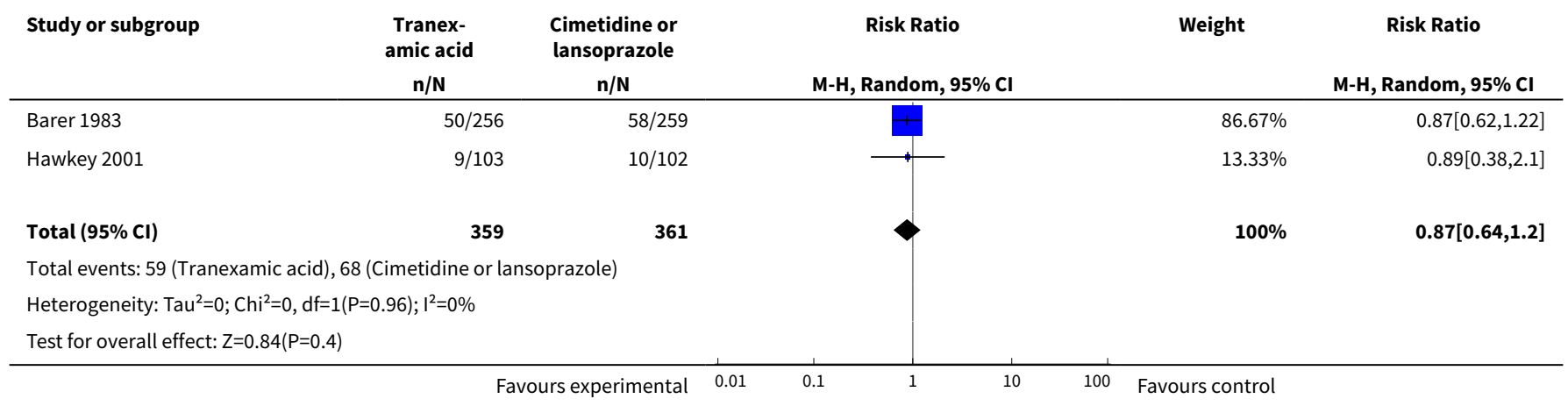

Analysis 2.3. Comparison 2 Tranexamic acid vs cimetidine or lansoprazole, Outcome 3 Surgery.

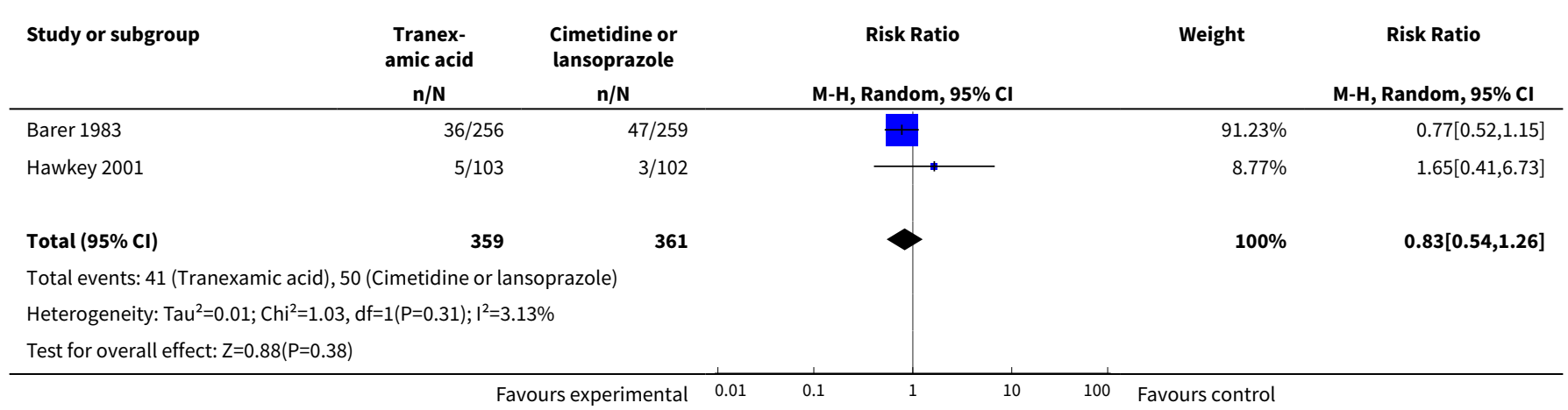


Analysis 2.4. Comparison 2 Tranexamic acid vs cimetidine or lansoprazole, Outcome 4 Transfusion.

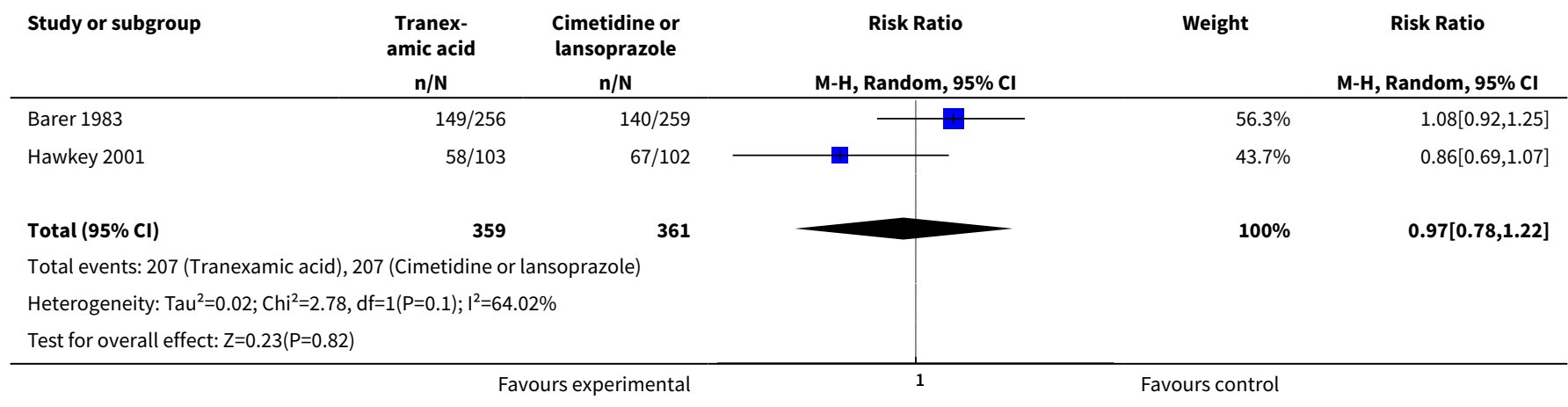

\section{ADDITIONAL TABLES}

Table 1. Adverse events

\begin{tabular}{|c|c|c|c|c|c|}
\hline \multirow[t]{2}{*}{ Trial } & \multicolumn{3}{|c|}{ Serious adverse events } & \multirow{2}{*}{$\begin{array}{l}\text { Non-serious adverse } \\
\text { events } \\
\text { Tranexamic acid }\end{array}$} & \multirow{2}{*}{$\begin{array}{l}\text { Non-serious } \\
\text { adverse events }\end{array}$} \\
\hline & $\begin{array}{l}\text { Tranexam- } \\
\text { ic acid }\end{array}$ & $\begin{array}{l}\text { Control } \\
\text { group }\end{array}$ & Intervention group not specified & & \\
\hline $\begin{array}{l}\text { Barer } \\
1983\end{array}$ & $\begin{array}{l}\text { Fatal stroke } \\
(n=1)\end{array}$ & $\begin{array}{l}\text { Confu- } \\
\text { sion } \\
(n=1)\end{array}$ & $\begin{array}{l}\text { Pulmonary embolism }(n=5) \text {. Myocardial } \\
\text { infarction }(n=8)\end{array}$ & None described & $\begin{array}{l}\text { Confusion }(n= \\
1)\end{array}$ \\
\hline $\begin{array}{l}\text { Biggs } \\
1976\end{array}$ & $\begin{array}{l}\text { None de- } \\
\text { scribed }\end{array}$ & $\begin{array}{l}\text { None de- } \\
\text { scribed }\end{array}$ & None described & $\begin{array}{l}\text { Thrombophlebitis at injec- } \\
\text { tion site }(n=3) \text {. Nausea or } \\
\text { headache }(n=4)\end{array}$ & $\begin{array}{l}\text { Throm- } \\
\text { bophlebitis at } \\
\text { injection site ( } n \\
=2) \text {. Nausea or } \\
\text { headache }(n= \\
\text { 5). Fever }(n=2)\end{array}$ \\
\hline $\begin{array}{l}\text { Engquist } \\
1979\end{array}$ & $\begin{array}{l}\text { Pulmonary } \\
\text { embolism } \\
(n=2) \text {. My- } \\
\text { ocardial in- } \\
\text { farction ( } n \\
=2 \text { ) }\end{array}$ & $\begin{array}{l}\text { Cerebral } \\
\text { infarction } \\
(n=2)\end{array}$ & None described & None described & None described \\
\hline $\begin{array}{l}\text { Hawkey } \\
2001\end{array}$ & $\begin{array}{l}\text { None de- } \\
\text { scribed }\end{array}$ & $\begin{array}{l}\text { None de- } \\
\text { scribed }\end{array}$ & $\begin{array}{l}\text { Several participants experienced throm- } \\
\text { boembolic complications. The numbers } \\
\text { were described as not significantly differ- } \\
\text { ent in treatment and control groups, but } \\
\text { no specific data are provided }\end{array}$ & None described & None described \\
\hline $\begin{array}{l}\text { Holstein } \\
1987\end{array}$ & $\begin{array}{l}\text { None de- } \\
\text { scribed }\end{array}$ & $\begin{array}{l}\text { Cerebral } \\
\text { infarction } \\
(n=2)\end{array}$ & $\begin{array}{l}\text { Five additional participants were exclud- } \\
\text { ed as the result of thromboembolic dis- } \\
\text { ease, but whether these participants } \\
\text { were randomly assigned to tranexamic } \\
\text { acid or placebo is not reported }\end{array}$ & $\begin{array}{l}\text { Nausea and vomiting, } \\
\text { tachycardia }(n=3) \text {. Hy- } \\
\text { potension }(n=3) \text {. Throm- } \\
\text { bophlebitis at injection } \\
\text { site }(n=2) \text {. Deep venous } \\
\text { thrombosis }(n=1)\end{array}$ & None described \\
\hline
\end{tabular}




\section{AP PEN DICES}

\section{Appendix 1. CENTRAL search strategy}

\section{CENTRAL July 2014}

\#1 stomach or antrum or antral or pyloric or pylorus or gastri* or epigastr* or duodenal or duodenum or gastro-duodenal or gastroduodenal or oeso ${ }^{\star} \mathrm{ag}^{\star}$ or esp ${ }^{\star} \mathrm{ag}^{\star}$ or upper GI or UGI or upper gastrointestinal

$\# 2 \mathrm{~h}^{\star}$ emorrhag* $^{\star}$ or bleed ${ }^{\star}$ or re-bleed ${ }^{\star}$ or rebleed*

\#3 (\#1 AND \#2)

\#4 MeSH descriptor Gastrointestinal Hemorrhage explode all trees

\#5 Gastrointestinal Hemorrhage

\#6 h*ematemesis

\#7 (\#3 OR \#4 OR \#5)

\#8 tranexamic acid or amchafibrin or anvitoff or cyklokapron or Espercil or exacyl or lysteda or spotof or t-amcha or tranhexamic acid or transamin or Transcam or ugurol

\#9 (\#7 AND \#6)

\section{Appendix 2. MEDLINE search strategy}

\section{Ovid MEDLINE 1950 to July 2014}

1. (stomach or antrum or antral or pyloric or pylorus or gastri\$ or epigastr\$ or duodenal or duodenum or gastro-duodenal or gastroduodenal or oeso*ag* or esp^ag* or "upper GI" or UGI or "upper gastrointestinal ").mp. [mp=title, original title, abstract, name of substance word, subject heading word, unique identifier]

2. ( $h^{\star}$ emorrhag\$ or bleed\$ or re-bleed\$ or rebleed\$).mp. [mp=title, original title, abstract, name of substance word, subject heading word, unique identifier]

\section{1 and 2}

4. exp Gastrointestinal Hemorrhage/

5. $h^{\star}$ ematemesis.mp. [mp=title, original title, abstract, name of substance word, subject heading word, unique identifier]

6. or/3-5

7. ("tranexamic acid" or amchafibrin or anvitoff or cyklokapron or Espercil or exacyl or lysteda or spotof or t-amcha or "tranhexamic acid" or transamin or Transcam or ugurol).mp. [mp=title, original title, abstract, name of substance word, subject heading word, unique identifier]

\section{6 and 7}

9. randomized controlled trial.pt.

10. controlled clinical trial.pt.

11. randomized.ab.

12. placebo.ab.

13. drug therapy.fs.

14. randomly.ab.

15. trial.ab.

16. groups.ab. 
17. or/9-16

18. exp animals/ not humans.sh.

19. 17 not 18

20. 8 and 19

\section{Appendix 3. EMBASE search strategy}

\section{EMBASE 1980 to July 2014}

1. (stomach or antrum or antral or pyloric or pylorus or gastri\$ or epigastr\$ or duodenal or duodenum or gastro-duodenal or gastroduodenal or oeso*ag* or esp^ag* or "upper GI" or UGI).mp. [mp=title, abstract, subject headings, heading word, drug trade name, original title, device manufacturer, drug manufacturer name]

2. ( $\mathrm{h}^{\star}$ emorrhag\$ or bleed\$ or re-bleed\$ or rebleed\$).mp. [mp=title, abstract, subject headings, heading word, drug trade name, original title, device manufacturer, drug manufacturer name]

\section{1 and 2}

4. gastrointestinal hemorrhage/

5. duodenum bleeding/ or stomach hemorrhage/ or upper gastrointestinal bleeding/

6. $h^{\star}$ ematemesis.mp. [mp=title, abstract, subject headings, heading word, drug trade name, original title, device manufacturer, drug manufacturer name]

7. or/3-6

8. ("tranexamic acid" or amchafibrin or anvitoff or cyklokapron or Espercil or exacyl or lysteda or spotof or t-amcha or "tranhexamic acid" or transamin or Transcam or ugurol).mp. [mp=title, abstract, subject headings, heading word, drug trade name, original title, device manufacturer, drug manufacturer name]

9. 7 and 8

10. Clinical trial/

11. Randomized controlled trial/

12. Randomization/

13. Single-Blind Method/

14. Double-Blind Method/

15. Cross-Over Studies/

16. Random Allocation/

17. Placebo/

18. Randomi?ed controlled trial\$.tw.

19. Rct.tw.

20. Random allocation.tw.

21. Randomly allocated.tw.

22. Allocated randomly.tw.

23. (allocated adj2 random).tw.

24. Single blind\$.tw.

25. Double blind\$.tw. 
26. ((treble or triple) adj blind\$).tw.

27. Placebo\$.tw.

28. Prospective study/

29. or $/ 10-28$

30. Case study/

31. Case report.tw.

32. Abstract report/ or letter/

33. or/30-32

34. 29 not 33

35.9 and 34

Appendix 4. Science Citation Index search strategy

\# 7 \#6 AND \#5

\# 6 TS=(random ${ }^{\star}$ or blind ${ }^{\star}$ or placebo* or meta-analysis)

\# 5 \#4 AND \#3

\# 4 TS=(tranexamic acid)

\# 3 \#2 AND \#1

\# 2 TS=(oeso*ag* or eso*ag* or stomach or gastric or ventricular or duodenum)

\# 1 TS=(bleeding or hemorrhage or haemorrhage or re-bleeding or (recurren* and (bleed ${ }^{\star}$ or haemorrhage or hemorrhage)))

\section{Appendix 5. International Clinical Trials Registry Platform (ICTRP) search strategy}

\section{ICTRP July 2014}

(bleeding OR "BLEEDING" OR "Blood Loss" OR "EXTRAVASATION BLOOD" OR "HAEMORRHAGE NOS" OR "HEM" OR "hemorrhage" OR "HEMORRHAGE (NOS)" OR "HEMORRHAGE NOS" OR "Hemorrhage, unspecified" OR "Hemorrhages" OR "Loss of blood" tranexamic acid OR "Acid, Tranexamic" OR "AMCA" OR "AMCHA" OR "Cyclokapron" OR "Cyklokapron" OR "t-AMCHA" OR "TRANEXAMIC ACID" OR "trans-4(Aminomethyl)cyclohexanecarboxylic Acid" AND (tranexamic acid OR "Acid, Tranexamic" OR "AMCA" OR "AMCHA" OR "Cyclokapron" OR "Cyklokapron" OR "t-AMCHA" OR "TRANEXAMIC ACID" OR). "trans-4-(Aminomethyl)cyclohexanecarboxylic Acid")).

\section{Appendix 6. Search results}

Eighty records were identified by initial electronic searches of the following databases.

- CENTRAL: 10 citations.

- MEDLINE: 22 citations.

- EMBASE: 62 citations.

- Science Citation Index: 6 citations.

Thirty-seven additional records were identified in the search update performed July 2014 (Figure 1).

\section{WHAT'S NEW}

\begin{tabular}{lll}
\hline Date & Event & Description \\
\hline 29 July 2014 & New search has been performed & $\begin{array}{l}\text { We originally planned to perform separate analyses on contin- } \\
\text { ued bleeding and rebleeding, but we were unable to extract the } \\
\text { necessary data from the included trials }\end{array}$ \\
\end{tabular}




\begin{tabular}{lll}
\hline Date Event Description & Den
\end{tabular}

We have updated the assessment of bias according to the recommendations provided in the Cochrane Handbook for Systematic Reviews of Interventions of The Cochrane Collaboration

29 July 2014

New citation required but conclusions

have not changed
One additional randomised controlled trial has been included in the analyses. The addition of this trial has not changed our conclusions.

\section{CONTRIBUTIONS OF AUTHORS}

LLG drafted the review and performed the statistical analyses. SLK and ELA participated in interpretation of the results and revision of the review. All review authors have approved the final version.

\section{DECLARATIONS OF INTEREST}

None of the review authors has reported any conflicts of interest with regard to the present work.

CB is the proprietor of Systematic Research Ltd and was paid by the CUGPD Editorial Group for her contributions to this review.

\section{SOURCES OF SUPPORT}

\section{Internal sources}

- The present review did not receive funding, Other.

\section{External sources}

- No sources of support supplied

\section{DIFFERENCES BETWEEN PROTOCOL AND REVIEW}

We updated the review in 2014 to comply with MECIR standards for the conduct and reporting of systematic reviews. We updated the format of the review for clarity and provided the following information about our methods.

- We included adverse effects as a primary outcome (formerly a secondary outcome) to comply with recent guidance on conduct and presentation of the systematic review.

- We clarified that because of the risk of selection bias in the allocation of participants to intervention or control groups and bias in the administration of collateral interventions, we did not include cluster-randomised trials.

- For trials with multiple intervention groups, we partitioned the numbers of participants in individual allocation arms into pair-wise comparisons.

- We used simple imputation to evaluate the potential influence of missing data: imputing failures, imputing successes, worst- and bestcase.

- We provided additional explanations of our assessment and reporting of heterogeneity for clarity; our methods remain unchanged.

- We performed all meta-analyses using both random-effects and fixed-effect models. Fixed-effect meta-analyses are reported only when results of the two models differ (e.g. one model shows no difference between interventions and the other shows an intervention effect).

- We performed separate analyses of trials on tranexamic acid versus placebo or no intervention and trials on tranexamic acid versus antiulcer drugs. We performed subgroup analyses of trials with low risk of bias based on assessment of the separate domains. We also analysed subgroups of trials that used endoscopic therapy and trials published in English or Russian.

- We performed an analysis when all participants with missing outcome data were included as treatment failures, and we used a perprotocol analysis to evaluate the influence of missing data when we excluded participants with missing outcome data.

- For analyses with at least 10 trials, we planned to assess reporting biases and other dissemination biases on the basis of funnel plots (Higgins 2011) and regression analyses by using Harbord's modified test (Harbord 2006). Our analyses included only eight trials; therefore we did not carry out statistical analysis of reporting bias.

- We performed a post hoc trial sequential analysis to evaluate the risk of bias associated with cumulative testing and to evaluate futility in assessment of mortality and bleeding (Higgins 2008; Wetterslev 2008). We performed the analysis with power set to $80 \%$, alpha to $5 \%$, model-based diversity and relative risk reduction (RRR) to $25 \%$. We set the control group incidence to $8 \%$ in our analysis of mortality and to $18 \%$ in our analysis of bleeding. 
- We prepared a 'Summary of findings' table (Guyatt 2008) using GRADEpro software (Gradepro 3.6) and included information on results of our primary outcomes in relation to risk of heterogeneity, duration of follow-up and quality of the evidence.

\section{NDEX TERMS}

\section{Medical Subject Headings (MeSH)}

Administration, Oral; Aluminum Hydroxide [therapeutic use]; Anti-Ulcer Agents [therapeutic use]; Antifibrinolytic Agents [adverse effects] [*therapeutic use]; Cimetidine [therapeutic use]; Drug Combinations; Endoscopy, Gastrointestinal; Gastrointestinal Hemorrhage [ ${ }^{\star}$ drug therapy] [mortality]; Injections, Intravenous; Lansoprazole [therapeutic use]; Magnesium [therapeutic use]; Magnesium Hydroxide [therapeutic use]; Randomized Controlled Trials as Topic; Tranexamic Acid [adverse effects] [therapeutic use]

\section{MeSH check words}

Humans 